\title{
Thermal Methods for Investigating Ground-Water Recharge
}

\author{
By Kyle W. Blasch, Jim Constantz, and David A. Stonestrom
}

\section{Introduction}

Recharge of aquifers within arid and semiarid environments is defined as the downward flux of water across the regional water table. The introduction of recharging water at the land surface can occur at discreet locations, such as in stream channels, or be distributed over the landscape, such as across broad interarroyo areas within an alluvial groundwater basin. The occurrence of recharge at discreet locations is referred to as focused recharge, whereas the occurrence of recharge over broad regions is referred to as diffuse recharge. The primary interest of this work is focused recharge, but regardless of the type of recharge, estimation of downward fluxes is essential to its quantification.

Direct measurement of water flux in the subsurface is difficult, prompting investigators to pursue indirect methods. Geophysical approaches that exploit the coupled relation between heat and water transport provide an attractive class of methods that have become increasingly reliable and widely used in investigations of recharge-for example, in chapters $\mathrm{D}-\mathrm{H}, \mathrm{J}$, and $\mathrm{K}$ of this volume. This appendix reviews the application of heat to the problem of recharge estimation. Geophysical methods other than heat are presented in appendix 2 .

Tutorials on measuring and modeling heat as a tracer of hydrologic processes have appeared elsewhere (Stonestrom and Blasch, 2003; Niswonger and Prudic, 2003). The objective of this appendix is to provide a fairly complete account of the theoretical underpinnings together with a comprehensive review of thermal methods in practice.

Like chemical tracers, heat can come from natural sources or be intentionally introduced to infer transport properties and aquifer recharge. The admission and redistribution of heat from natural processes such as insolation, infiltration, and geothermal activity can be used to quantify subsurface flow regimes (fig. 1). Heat is well suited as a ground-water tracer because it provides a naturally present dynamic signal and is relatively harmless over a useful range of induced perturbations; however, artificially exchanging heat with ground-water systems can change the hydraulic properties and fluid fluxes of interest. Specific properties that depend on temperature include viscosity, density, and surface tension, all of which affect hydraulic conductivity and fluid flow.

Thermal methods have proven valuable for recharge investigations for several reasons. First, theoretical descrip- tions of coupled water-and-heat transport are available for hydrologic processes most often encountered in practice. These include land-surface mechanisms such as radiant heating from the sun, radiant cooling into space, and evapotranspiration, in addition to the advective and conductive mechanisms that usually dominate at depth. Second, temperature is theoretically well defined and readily measured. Third, thermal methods for depths ranging from the ground surface to depths of hundreds of meters are based on the same physical principles. Finally, numerical codes for simulating heat and water transport are widely available.

Investigators began using subsurface temperatures to delineate recharge areas and infer directions of ground-water flow about the turn of the 20th century. During the 1960s, analytical and numerical solutions for simplified heat- and fluid-flow problems became available. These solutions, though one-dimensional and otherwise restricted, provided a strong impetus for applying thermal methods to problems of liquid and vapor movement in systems ranging from soils to geothermal reservoirs.

The combination of fast processors, massive data storage, and efficient matrix techniques now provide numerical solutions to complex, three-dimensional transport problems. These solutions allow researchers to take advantage of the considerable information content routinely achievable in high-accuracy temperature work.

\section{Theoretical Framework}

Darcy (1856) demonstrated that the movement of water through a porous medium is the product of the medium's hydraulic conductivity and the gradient of total head, where total head is composed of a gravitational and a pressure component. Electrical, chemical, and thermal gradients represent potential-energy fields that also are capable of inducing fluid flow. In most cases, induced fluid, chemical, and energy fluxes can be approximately conceptualized as linearly independent summations of the products of gradients acting on a given domain times a set of corresponding coupling ("phenomenological") coefficients, or constants of proportionality (Freeze and Cherry, 1979; Warrick, 2003). Following Warrick (2003), the hydraulic flux $Q\left(\mathrm{~L} \mathrm{t}^{-1}\right)$ is given as the summation of pressure, gravitational, and thermal gradients, $X\left(\mathrm{~L} \mathrm{~L}^{-1}\right)$, multiplied by the coupling coefficients, $L\left(\mathrm{~L} \mathrm{t}^{-1}\right)$ : 


$$
Q_{i}=\sum_{j=1}^{3} L_{i j} X_{j}
$$

where the subscript $j$ denotes pressure, gravitational, and thermal gradients, and the subscript $i$ denotes water in the present case or, with appropriate changes to units, heat.

Darcy's law is thus a special case of equation 1 . The flow of liquid water through isothermal but variably saturated media is induced by a hydraulic gradient composed of pressure and gravitational terms:

$$
Q=L_{11} X_{1}+L_{12} X_{2}
$$

Substitution of gradients and coupling coefficients produces:

$$
Q=-K_{H}(\theta) \nabla \psi-K_{H}(\theta) \nabla z
$$

where $K_{H}$ is the hydraulic conductivity $\left(\mathrm{L} \mathrm{t}^{-1}\right)$, which depends strongly on soil-water content $\theta\left(\mathrm{L}^{3} \mathrm{~L}^{-3}\right), \psi$ is pressure head $(\mathrm{L})$, and $z$ is elevation head (L). The symbol $\nabla$ is the del operator denoting (here) the gradient of a scalar in three dimensions.
Equation 3 can be generalized to include temperature gradients and vapor flow:

$$
Q=-D_{\theta} \nabla \theta-D_{T} \nabla T-K_{H}(\theta) \nabla z
$$

where $Q$ is now the total water flux (vapor plus liquid) due to hydraulic, thermal, and temperature gradients $\left(\mathrm{L} \mathrm{t}^{-1}\right), D_{\theta}$ is the moisture diffusivity $\left(\mathrm{L}^{2} \mathrm{t}^{-1}\right)$, and $D_{T}$ is the sum of vapor and liquid thermal moisture diffusivity $\left(\mathrm{L}^{2} \mathrm{t}^{-1} \mathrm{~T}^{-1}\right)$. The first term on the right-hand side of equation 4 is a diffusionformalized hydraulic flux that is actually driven by a gradient in pressure head, which-with some restrictions-can be related to the gradient in moisture content by means of the soil-moisture characteristic $\psi(\theta)$. The second term is a liquid-plus-vapor diffusive flux driven by the temperature gradient. The third term is the gravitational hydraulic flux, written here for liquid water only. This latter simplification is possible because the specific density of liquid water is some 40-thousand times higher than water vapor at standard temperature and pressure.

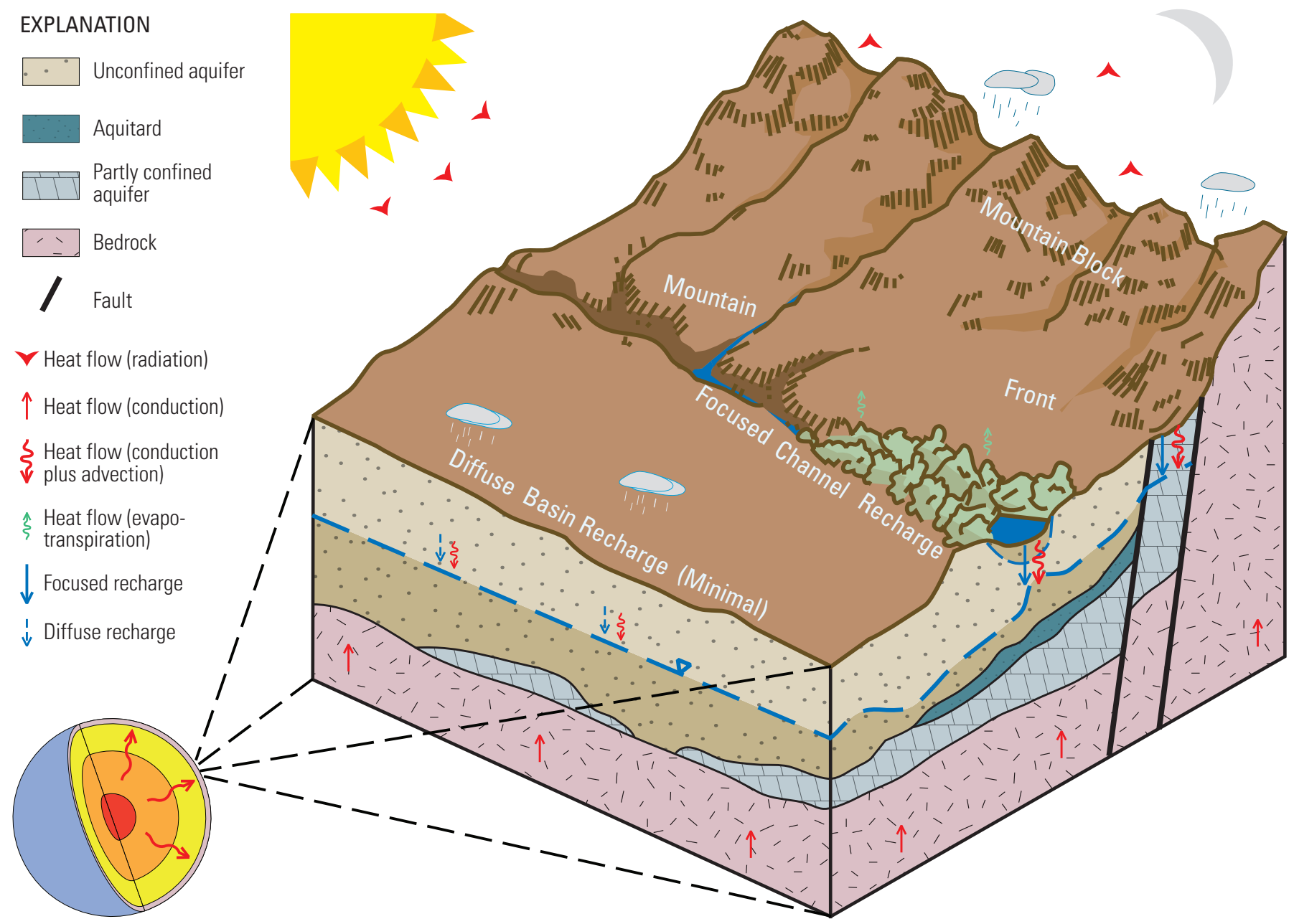

Figure 1. Conceptual model of coupled water and heat transport through focused (for example, channel and mountain block) recharge and diffuse (for example, basin) recharge processes. Thermal energy is sustained by radiant heating from the sun and geothermal heating from the Earth's interior. 


\section{Temperature Gradients}

Conditions frequently encountered in nature produce large gradients in hydraulic head that cause water at an initial temperature to flow into a new location with a contrasting temperature. For example, alpine streams can rapidly transport near-freezing meltwater to warmer portions of the channel at lower altitudes. Irrigation water applied to agricultural fields often has a sharply contrasting temperature from that of ambient soils and subsoil sediments.

Fluid movement is usually dominated by pressure and elevation gradients rather than by temperature gradients, at least for high-to-medium water contents. Nevertheless, Hoekstra and Miller (1967) documented thermally induced migration of liquid water at the pore scale in partially frozen soils. And at larger scales, Bredehoeft and Papadopulos (1965) described redistribution of water in the saturated zone due to density gradients arising from spatial variation in temperature.

Arid and semiarid sediments are often far from saturation. Because the hydraulic conductivity of dry materials is many orders of magnitude below that of water-saturated materials, naturally occurring hydraulic gradients-though often large-are insufficient to drive appreciable amounts of liquid movement. Over an appreciable range of low-tointermediate water contents, temperature gradients tend to dominate the movement of water, predominantly as vapor (Philip and de Vries, 1957; Rose, 1963; Walvoord and others, 2004). Scanlon and Milly (1994) simulated thermally driven vapor fluxes in near-surface sediments of a semiarid basin in the Chihuahuan Desert. Acting over many years, thermally induced vapor movement accounted for the deepening of tritiated water $\left({ }^{3} \mathrm{H}-\mathrm{O}-{ }^{1} \mathrm{H}\right)$ relative to radioactive chloride ions $\left({ }^{36} \mathrm{Cl}^{-}\right)$generated by above-ground nuclear-weapons testing in the 1950s and 1960s (Scanlon, 1994; Scanlon and Milly, 1994). As a practical matter, early designs for heat-pulse probes produced problematic amounts of moisture movement due to induced temperature gradients (Ren and others, 1999; Ren and others, 2000).

\section{Distribution of Heat in the Subsurface}

The background distribution of temperature in the subsurface reflects the flows of thermal energy from two primary sources-the cyclic radiant heating and cooling from above, and nearly constant geothermal heating from below (fig. 1). Spatial flows of heat are strongly influenced by climate and geology. Shallow temperature regimes vary with latitude, altitude, topography, soil and sediment properties, shading, and vegetation, in addition to sources and sinks of heat. Soil and sediment properties include composition-particularly soil-organic-matter content-and structure, layering, and water content.

Subsurface sources of heat include microbial metabolism, radioactive decay, magmatic intrusions, and tectonic activity. Geothermal energy provides heating from deep within the Earth's crust, mantle, and core. The outward propagation of heat from the planet's interior results in a characteristic geothermal gradient. The shape of the geothermal profile reflects (1) the local thickness and thermal properties of the crustal rocks through which the heat is escaping towards space, (2) radiogenic additions of heat from local crustal rocks, and (3) regional magmatic emplacement (Lachenbruch and Sass, 1977).

At the land surface, temporal fluctuations in temperature due to changes in deep geothermal heating are negligible compared to those due to (1) diurnal fluctuations in incoming (predominantly shorter wave) and outgoing (predominantly longer wave) radiation and (2) sensible heat exchanges with overlying air. Bare-soil surface temperatures typically lag the radiant diurnal cycle by approximately one hour. Surface heating of wet soils is decreased appreciably by the large latent heat of evaporating water. For soils with vegetative cover, soil surface temperatures are reduced as a consequence of shade, transpiration, and the thermal mass of the canopy. Under a vegetated canopy, soil-surface temperatures change mostly by contact with air, and thus lag the daily cycle of air temperature rather than the radiant diurnal cycle.

The cyclical nature of vertical heat exchange is manifested in characteristic downward-pinching temperature envelopes (Heath, 1964; Lapham, 1987). As oscillating temperature signals propagate downward from the surface, heat is exchanged with a progressively greater mass of sediments. This results in signal attenuation manifested in a decrease in the width of temperature envelopes with depth (fig. 2). Annual temperature envelopes capture the range and persistence of annual cooling and heating and extend wider and deeper than diurnal temperature envelopes. Temperature envelopes at depth narrow to a point where cyclic variations are no longer detectable. As shown in subsequent sections, the depths of temperature envelopes depend sensitively on hydraulic fluxes within the sediments (fig. 2).

\section{Heat Propagation Through Conduction}

If the movement of fluids is temporarily not considered, then the flow of thermal energy from a radiatively heated or geothermal source, for example, can be described by Fourier's first two laws of heat conduction. Fourier's first law states that heat flow in a homogeneous material is directly proportional to the temperature gradient:

$$
q_{T}=-K_{T}(\theta) \nabla T
$$

where $q_{T}$ is the thermal (heat) flux $\left(\mathrm{E} \mathrm{L}^{-2} \mathrm{t}^{-1}\right)$ and $K_{T}$ is the thermal conductivity $\left(\mathrm{E} \mathrm{L}^{-1} \mathrm{t}^{-1} \mathrm{~T}^{-1}\right)$. Dimensions $\mathrm{E}, \mathrm{L}, \mathrm{T}$, and $\mathrm{t}$ represent energy, length, temperature, and time. The thermal conductivity is approximately independent of temperature but varies with water content, as indicated. Equation 5 is analogous to Darcy's law (eqn. 3). 


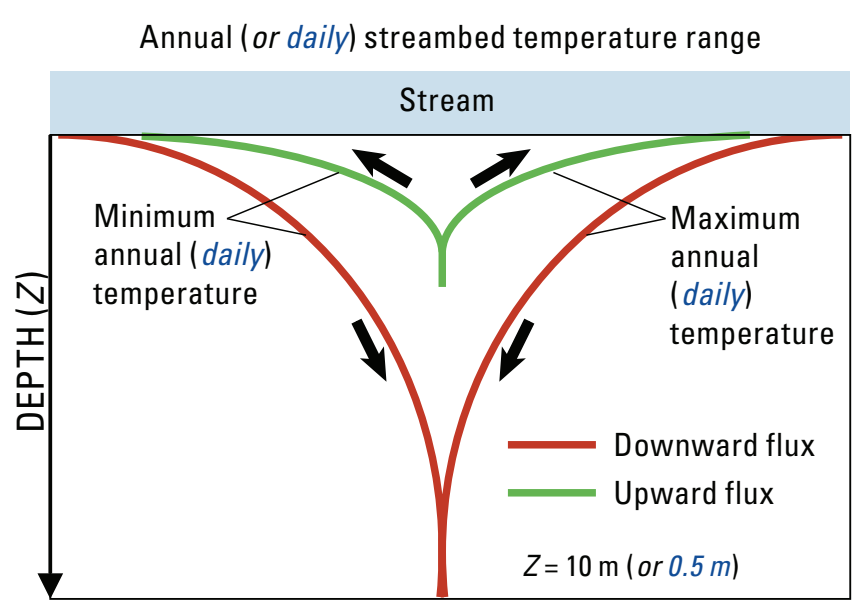

TEMPERATURE

Figure 2. Ranges of sediment temperatures versus depth, $Z$, for gaining stream conditions (green lines) compared with losing stream conditions (red lines), over daily or annual cycles. The depth at which the temperature becomes constant depends upon the upward or downward flow of water through the sediments. For annual profiles, this depth may be 10 meters or more for downward flow versus less than a few meters for upward flow. For diurnal cycles, the depths at which temperatures become constant are shallower by the square root of (365/1) for a neutral flux. (Modified from Constantz and Stonestrom, 2003.)

Fourier's second law of heat conduction states that the rate of change in thermal energy stored in a volume element of thermally conducting medium is equal to the divergence of the heat flux:

$$
\rho_{s} c_{s} \frac{\partial T}{\partial t}=-\nabla \cdot q_{T}
$$

where $\rho_{s}$ is the mass density $\left(\mathrm{M} \mathrm{L}^{-3}\right)$ and $c_{s}$ is the specific heat capacity $\left(\mathrm{E} \mathrm{M}^{-1} \mathrm{~T}^{-1}\right)$ of the medium (in this case soil or sediment).

Combining equations 5 and 6 , and defining thermal diffusivity as

$$
\alpha_{T}=\frac{K_{T}(\theta)}{\rho_{s} c_{s}}
$$

produces an equation for the conductive flow of heat in four dimensions:

$$
\frac{\partial T}{\partial t}=\frac{K_{T}(\theta)}{\rho_{s} c_{s}} \nabla^{2} T=\alpha_{T}(\theta) \nabla^{2} T
$$

Conductive heat transport occurs by molecule-to-molecule transfer of thermal energy in solids and semi-solids, in which the molecules have no long-range motion. As with all forms of heat, the movement of energy is from higher temperature to lower temperature.
Equation 8 can be solved analytically or numerically depending on the complexity of the boundary conditions and system geometry. In one dimension, the governing equation can be written (Carslaw and Jaeger, 1959; van Wijk and de Vries, 1963a):

$$
\frac{\partial T}{\partial t}=-\frac{K_{T}}{\rho_{s} c_{s}} \frac{\partial^{2} T}{\partial z^{2}}
$$

where $z$ is the depth below the land surface (L). Equation 9 assumes a homogeneous, isotropic medium in which the thermal conductivity is constant. The diurnal temperature signal at the upper boundary, $T\left(z_{o}, t\right)$, is frequently approximated by a sinusoidal forcing function:

$$
T\left(z_{o}, t\right)=T_{m}+T_{a} \sin \left[\left(\frac{2 \pi}{P}\right) \cdot\left(t-t_{o}\right)\right]
$$

where $T_{a}$ is the amplitude of the temperature wave at the surface (T), $T_{m}$ is the mean temperature (T), $P$ is the period of the wave $(\mathrm{t})$, and $t_{\mathrm{o}}$ is the time that the amplitude is zero $(\mathrm{t})$.

The solution to equation 9 with an upper-boundary condition represented by equation 10 and a lower-boundary condition $T=T_{m}$ at infinite depth is:

$$
T(z, t)=T_{m}+T_{a} \exp \left(\frac{-z}{D}\right) \cdot \sin \left[\left(\frac{2 \pi}{P}\right) \cdot\left(t-t_{0}\right)-\frac{z}{D}\right]
$$

where $D$ is the damping depth $(\mathrm{L})$ :

$$
D=\left(\frac{P \alpha_{s}}{\pi}\right)^{1 / 2}
$$

The damping depth conveys several useful attributes of the thermal wave, including its speed of propagation:

$$
v=2 \pi \frac{D}{P} \text {. }
$$

In addition, the amplitude of the temperature wave falls to $\mathrm{e}^{-1}$ $(\approx 0.37)$ at a depth $D$. The phase of the temperature wave shifts 180 degrees with respect to the surface at a depth $z=D \pi$.

Equation 13 is suitable for describing annual as well as diurnal cycles. The thermal wave described by the annual cycle can penetrate about 19 times deeper than the diurnal wave, the square root of 365 being approximately 19. Peerklamp (1944) provides solutions for amplitude and phase of thermal waves as a function of depth for the case of layered systems.

The addition of nonflowing water in the pore space causes an increase in the volumetric heat capacity as well as the thermal conductivity. To the degree that heat is transported only by conduction, the solution just given remains applicable. The change in thermal conductivity is more pronounced than the change in the thermal heat capacity, resulting in an increased thermal diffusivity. As shown above, the damping 
depth of the thermal wave is directly proportional to the square root of the thermal diffusivity. Thus, contrary to what might be expected, increasing saturations result in a faster (and deeper) propagation of a thermal signal into the profile (fig. 3).

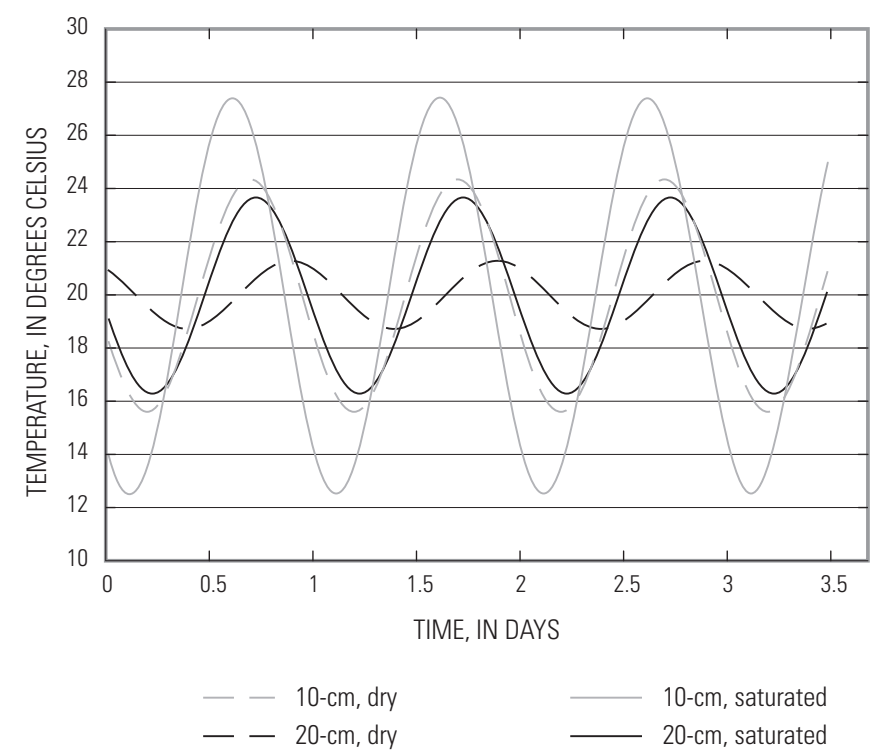

Figure 3. Conductive heat transport in a sandy soil at $10-\mathrm{cm}$ and 20-cm depths for dry (dashed lines) and saturated (solid lines) water contents, computed with typical thermal properties of Rillito Creek sediments (chapter $\mathrm{H}$, this volume).

\section{Heat Propagation Through Conduction plus Advection}

The previous section considered only conductive heat transport. Advective heat transport associated with pore-water movement changes the distribution of temperatures described by equation 11 . Advection is the transport of heat by the organized movement of fluid from one location to another. The term "convection" as used especially in the older literature is synonymous with the term "advection" as used here. In the context of ground-water recharge, the advection of heat is primarily through the flow of liquid water and thus depends primarily on hydraulic-flux density, water content, and initial and boundary conditions.

The nonisothermal transport of water through a variably saturated porous medium can be described by the following generalization of the Richards equation:

$$
\frac{\partial \theta}{\partial t}=\nabla \cdot\left(D_{T} \nabla T\right)+\nabla \cdot\left(D_{\theta} \nabla \theta\right)-\frac{\partial K(\theta)}{\partial z},
$$

where $D_{T}$ is the thermal moisture diffusivity $\left(\mathrm{L}^{2} \mathrm{t}^{-1} \mathrm{~T}^{-1}\right), D_{\theta}$ is the hydraulic moisture diffusivity $\left(\mathrm{L}^{2} \mathrm{t}^{-1}\right)$, and $t$ is time. Richards' original equation combined the equation of conti- nuity with Darcy's law for isothermal conditions to describe the change of water content due to capillary and gravitational gradients alone (Richards, 1931).

The corresponding heat-transport equation balances the change in stored thermal energy with the inflow and outflow of heat through conduction, advection, dispersion, and sources and sinks within the porous medium (Kipp, 1987; Nasser and Horton, 1992; Healy and Ronan, 1996). The following equation represents contributions from these sources in homogeneous and isotropic sediments:

$$
\begin{aligned}
& {\left[\theta C_{w}+(1-\varphi) C_{s}\right] \frac{\partial T}{\partial t}=\nabla \cdot\left[K_{T}(\theta) \nabla T\right]+,} \\
& \nabla \cdot\left(\theta C_{w} D_{H} \nabla T\right)-\nabla \theta C_{w} Q T+q^{*} C_{w} T^{*}
\end{aligned}
$$

where $\varphi$ is the sediment porosity $\left(\mathrm{L}^{3} \mathrm{~L}^{-3}\right), C_{w}$ and $C_{s}$ are the volumetric heat capacities of water and bulk sediment, respectively, $K_{H}$ is the bulk thermal conductivity, $D_{H}$ is the hydrodynamic dispersion tensor $\left(\mathrm{L}^{2} \mathrm{t}^{-1}\right), Q$ is the hydraulic flux $\left(\mathrm{L} \mathrm{t}^{-1}\right)$, $q^{*}$ is the rate of water added per volume of porous medium from an external or internal source $\left(\mathrm{t}^{-1}\right)$, and $T^{*}$ is the temperature of that water source $(\mathrm{T})$.

The left-hand side of equation 15 represents the change in thermal energy stored in the liquid and solid phases; heat stored in the gas phase is assumed to be negligible. The change in stored thermal energy is balanced by the terms on the right, beginning with the energy transported by thermal conduction followed by the energy transported by thermomechanical dispersion. The remaining two terms represent the energy transported by advection and sources or sinks of heat within the domain. Thermomechanical dispersion caused by mixing of water within the porous medium is treated by a hydrodynamic dispersion tensor term $D_{H}$ analogous to that from solute-transport theory, defined as follows (Healy and Ronan, 1996):

$$
D_{H_{i, j}}=\alpha_{T}|v| \delta_{i j}+\left(\alpha_{L}-\alpha_{T}\right)\left(v_{i} v_{j}\right) /|v|
$$

where $\alpha_{T}$ is the transverse dispersivity of the porous medium (L), $|v|$ is the magnitude of the hydraulic flux-density vector $\left(\mathrm{L} \mathrm{t}^{-1}\right), v_{i}$ is the $i$ th component of the hydraulic flux-density vector $\left(\mathrm{L} \mathrm{t}^{-1}\right), \delta_{i j}$ is the Kronecker delta operator (equal to 1 if $i=j$; otherwise equal to 0$), \alpha_{L}$ is the longitudinal dispersion (L), and $i$ and $j$ are indices $(i=1,2,3 ; j=1,2,3)$ representing the orthogonal Cartesian directions. Heat transport is coupled to fluid flow not only through the thermal and hydraulic gradients, but also through the water-content- and temperaturedependent phenomenological coefficients.

The equations for coupled water and heat transport, 14-16, provide the mathematical foundation for the application of thermal methods to recharge investigations. Thermal methods can be grouped into shallow-, intermediate-, and deep-application ranges, although the boundaries between the depth ranges are not distinct. Similar mechanisms and principles apply to all ranges. 
A key factor differentiating shallow, intermediate, and deep thermal profiles with respect to recharge analysis is the periodicity or stability of the temperature profile. At shallow depths, aperiodic fluctuations in weather and radiation along with periodic fluctuations on diurnal and annual periods generate large transients in temperature. At intermediate depths temperature profiles are more stable, changing cyclically with the seasons, such that changes due to vertical water fluxes combine with the annual temperature cycle to produce temperature profiles intermediate between those of shallow, diurnally varying profiles and the nearly constant temperature profiles at depth (fig. 4). Temperature profiles at depth are mostly controlled by the interplay of water movement with deep-seated, upwardly directed geothermal gradients. Deep profiles tend to be stable, changing only on decadal or longer time scales in most cases. Shifts in temperature regimes at large depths indicate substantial changes in recharge conditions.

\section{Emergence of Thermal Methods}

Thermal methods of soil-moisture and ground-water investigations came into widespread use in the early to mid 1960s. Whereas earlier investigations, such as those of Smith (1910) and Rorabaugh (1956), used heat qualitatively to locate sources of ground-water recharge and ground-water flow paths, it was not until Suzuki (1960), Stallman (1965), and Bredehoeft and Papadopulos (1965) published analytical

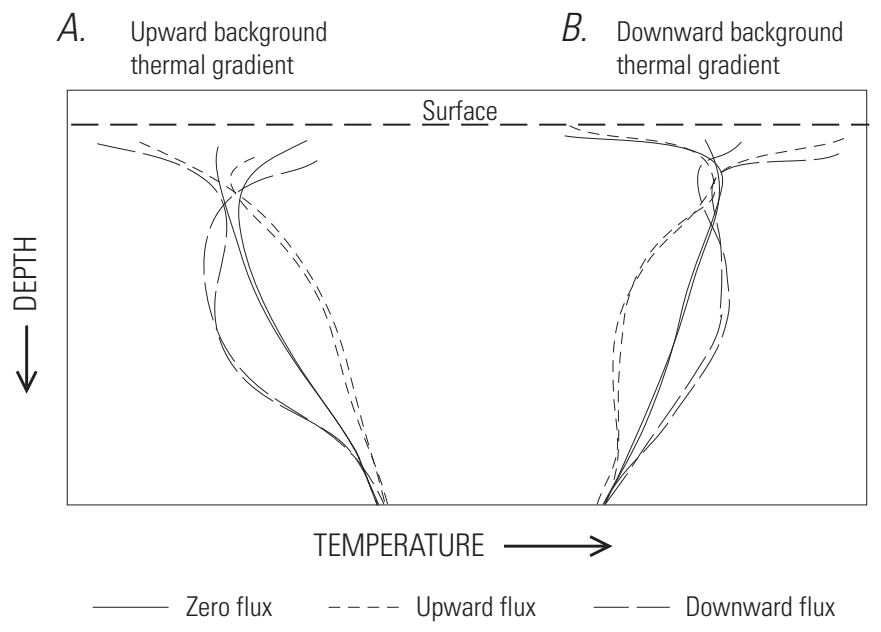

Figure 4. The influence of vertical water flow on the shape of background thermal gradients. Upward, zero, or downward fluxes of water superimposed on $A$, an upward (geothermal) background gradient, or $B$, a downward background thermal gradient. Example constructed from data obtained at Rillito Creek, Arizona (chapter $H$, this volume). solutions to the coupled heat and water transport equations that thermal methods for estimating rates of subsurface water movement came into general use. Suzuki (1960) used temperature measurements to estimate infiltration and deep percolation in rice paddies by assuming saturated, vertical, steady state flow in a homogeneous medium with a sinusoidal daily surface temperature. Suzuki presented an approximate analytical solution to a simplified form of equation 15, assuming the temperature at depth was equal to the mean surface temperature. For one-dimensional, vertical transport, the governing equation is (Suzuki, 1960):

$$
\frac{\partial T}{\partial t}=\frac{K_{T}}{c_{s} \rho_{s}} \frac{\partial^{2} T}{\partial z^{2}}-\frac{c_{w} \rho_{w}}{c_{s} \rho_{s}} v_{z}\left(\frac{\partial T}{\partial z}\right) .
$$

Stallman (1960; as reported in Stallman, 1963) independently developed a three-dimensional generalization of equation 17 from first principles and remarked that an analytical solution was available for the one-dimensional case, attributed to Robert E. Glover. Stallman (1965) published an exact solution for the one-dimensional problem solved approximately by Suzuki. Like Suzuki, Stallman represented the upper boundary condition as a sinusoidal temperature fluctuation; however, Stallman investigated the propagation of annual as well as diurnal temperature signals. Stallman estimated that his exact analytical solution could be used to detect percolation rates as low as $0.1 \mathrm{~cm} / \mathrm{d}$ by using annual temperature signals and $0.3 \mathrm{~cm} / \mathrm{d}$ by using diurnal signals. At lower velocities, heat transport through conduction would become dominant. Taniguchi and Sharma (1993) employed Stallman's (1965) one-dimensional solution to determine recharge beneath two forested sites near Perth, Australia. Ground-water recharge rates obtained by this method were consistent with results obtained with chemical tracers.

Additional early approaches to solving the one-dimensional coupled transport equation include a type-curve method developed by Bredehoeft and Papadopulos (1965), discussed in the following section, and a heat-balance method developed by Wierenga and others (1970). Wierenga developed the heatbalance method to model temperatures in irrigated soils. For purposes of analysis the soil is discretized into horizontal layers, and different mathematical approaches are used to simulate early and late-time behavior. For periods of infiltration and appreciable soil-water redistribution, interlayer transfers of heat are adjusted to match measured temperatures by algebraically adjusting transfers of water. After the transfer of water between layers becomes negligible, subsequent (conductiveonly) heat flow is modeled with an explicit finite-difference form of the one-dimensional heat equation. Taniguchi and Sharma (1993) evaluated the heat-balance method and found that, while useful for estimating water fluxes near the surface, its accuracy deteriorated quickly with depth. They concluded that the heat-balance method is limited to the upper two meters because changes in temperature below this depth could not be resolved with sufficient accuracy. 


\section{Early Thermal Methods for Estimating Deep Recharge}

The fact that ground-water movement in deep sediments causes anomalies in the Earth's geothermal gradients was realized by the 1930s (Van Orstrand, 1934; Bullard, 1939). Deviations from linearity in vertical thermal profiles were proposed as a means to identify the extent and thickness of low-permeability layers near the production interval of an aquifer (Norris and Spieker, 1962). The discovery of subterranean hot springs thousands of feet below land surface enabled Lovering and Morris (1965) to estimate amounts of fresh water coming from the surface versus geothermal water coming from depth on the basis of a simple conductive heat-flow and water-mixing model. Schneider (1972) used deviations in thermal profiles to qualitatively infer the presence of aquifer recharge beneath a losing reach of a river in the presence of ground-water pumpage.

Bredehoeft and Papadopulos (1965) presented a general analytical solution to the differential equation describing the steady flow of heat and fluid in the deep subsurface and showed how it could be used to estimate vertical ground-water velocities in and hydraulic conductivities of confining layers. The solution assumes vertical steady-state ground-water flow through a homogeneous layer. The authors presented type curves corresponding to various combinations of medium properties and flow rates. They estimated that with available thermometry one could detect Darcian water fluxes as small as $0.1 \mathrm{~cm} / \mathrm{d}$ in a $10-\mathrm{m}$ thick semiconfining layer. The type-curve method quickly became popular for determining ground-water velocities because it required minimal data collection and was easy to apply (Cartwright, 1970; Sorey, 1971; Cartwright, 1979, Boyle and Saleem, 1979).

Cartwright (1970) constructed contour maps of temperatures at 500 feet by linear interpolation of surface data and data from deep exploration boreholes throughout Illinois and compared them with theoretical maps derived from extrapolations of geothermal gradients measured at the bottom of the boreholes and the assumption of no fluid flow. The residuals of predicted minus interpolated temperatures showed regions of positive and negative anomalies corresponding to areas of inferred recharge and discharge. Cartwright (1970) applied the analysis of Bredehoeft and Papadopulos to estimate water movement at the basin scale and, in later work, to estimate ground-water movement between two aquifers (Cartwright, 1979). Similarly, Sorey (1971) calculated vertical flow velocities on the order of $0.3 \mathrm{~m} / \mathrm{yr}$ hundreds of feet below the land surface in semiarid basins in New Mexico and Colorado. Velocities from the type-curve method were similar to those from water-budget and pump-test analyses. Sorey recommended that the typecurve method be restricted to cases where the geology was well characterized and relatively simple. Stevens and others (1975) recommended that temperature profiles used in thermal analysis be measured in a borehole that has sat idle for several years, allows no circulation from one interval to another inside or along the outside of the casing, and has a diameter no greater than $5 \mathrm{~cm}$. Furthermore, they warned against using metal casing, which conducts heat preferentially, and cement-based grout, which generates heat while curing.

Numerical methods were also introduced starting in the 1970s to interpret temperature anomalies in terms of water movement. Supko (1970) measured temperatures in the unsaturated zone to delineate ground-water flow in the Tucson Basin of Arizona by using a "valley mapping function" developed from a numerical heat- and fluid-transport model. Areas of recharge and paths of subsequent ground-water movement were delineated by tracks of relatively low ambient subsurface temperatures.

\section{Expansion of Thermal Methods}

During the 1970s and early 1980s, field and numerical studies were conducted in Europe and the United States to determine the feasibility of storing thermal energy in confined and unconfined aquifers (Tsang and Hopkins, 1982). Data from field experiments greatly improved the understanding of fluid flow resulting from temperature gradients. Sophisticated numerical models of multiphase heat and fluid transport emerged. A large number of thermal investigations undertaken during this period, including modeling techniques and calibration methods, are summarized in Beck and others (1989).

During the past two decades, thermal methods have been increasingly applied to problems of water availability in arid and semiarid communities. Many of these communities depend on ground water as a primary source for agricultural, domestic, and industrial uses. As shown by the examples in chapters D-H, J, K (this volume), thermal methods have been increasingly applied to identify and enumerate channel infiltration and basin recharge. A major factor has been the improvement in field instrumentation, including temperature sensors and data-storage technology. A recent development is the use of fiber-optic-cable techniques - which, while relatively expensive, allow nearly continuous measurements of temperature in space and time (Day-Lewis and others, 2006; Selker and others, 2006; Gungle, 2007).

\section{Investigations of Channel Infiltration and Recharge}

Channel recharge is defined as recharge that originates as channel infiltration. Infiltration rates measured at the streambed provide upper bounds for channel recharge. They are upper bounds because some of the infiltrating water will be subsequently lost to evapotranspiration. Water evaporates directly from the channel following the cessation of ephemeral flow. In addition, water that moves laterally from the channel may also not reach the water table, returning instead to the atmosphere through evapotranspiration adjacent to the channel.

Thermal methods are advantageous for determining seepage losses because useful measurements can be obtained from 
the sediments beneath the channel surface. Buried sensors are less prone than surface instruments to loss by scour and deposition or damage by flood-borne debris. Measurements can be obtained during large flows that render surface measurements impractical and unsafe. Infrequent events are more easily captured. Traditional seepage losses are determined as the difference in stage-based discharge at two or more points along a reach. Stage-based estimates of discharge tend to be inaccurate, especially for large, non-steady flow events. Infiltration rates inferred by using thermal methods are essentially point measurements, differentiating them from seepage losses inferred by discharge measurements, which involve integration of infiltration rates along a reach.

Lapham (1987) monitored temperature profiles beneath streams to determine the magnitude and direction of water exchanges between streams and underlying aquifers. He modeled the coupled transport of water and heat by obtaining solutions to explicit finite-difference representations of equation 17. This approach allowed the use of measured (nonsinusoidal) temperature boundary conditions at the channel surface as well as a ground-water temperature not equal to the mean surface value. Lapham's approach provided simultaneous estimates of effective hydraulic conductivities and vertical flow rates for water.

Silliman and Booth (1993) identified characteristic thermographs of gaining and losing reaches of channels by measuring streamflow and sediment temperatures along a stream in Indiana. Gaining and losing reaches were readily identified by inspection of the amplitude of the diurnal temperature signal in the streambed versus in flowing water. Losing reaches were characterized by large thermal amplitudes associated with radiant daytime heating and nighttime cooling (fig. 5).

Gaining reaches were characterized by much smaller thermal amplitudes because ground water entering the stream from an underlying aquifer is buffered from diurnal forcing. Thus, temperature profiles within the streambed of a channel provide immediate information on gaining and losing portions of streams. Lee (1985) had previously used a similar analysis to identify areas of ground-water inflow and discharge in lakes. Constantz (1998) applied a similar analysis to identify gaining and losing reaches in alpine environments. Lawler (2002) identified reaches in a semiarid stream that were gaining and losing during different parts of the year. During winter the water table was above the altitude of the streambed, producing gaining conditions. During spring and summer ground-water pumping for agriculture together with riparian evapotranspiration dropped the water table below the streambed, producing losing conditions.

Silliman and others (1995) developed solutions to equation 17 for arbitrarily varying upper-boundary conditions by using the mathematical technique of superposition. The approach required the assumption of fully saturated conditions. Silliman and others used this approach in estimating stream-bed losses from temperatures measured at the base of the water column and at a depth of $25 \mathrm{~cm}$ in underlying stream-bed sediments.

\section{Pure Advection Solution}

Infiltration rates in the streambed vary widely. Wankiewicz (1984) analyzed thermal profiles beneath two streams in the Northwest Territories of Canada and concluded that thermal transport beneath one stream was almost entirely by conduction, whereas thermal transport beneath another stream was almost entirely by advection. The Peclet number can be used to assess the relative magnitude of advection and conduction for heat transport in ground-water recharge applications. The Peclet number is defined as follows (van der Kamp and Bachu, 1989):
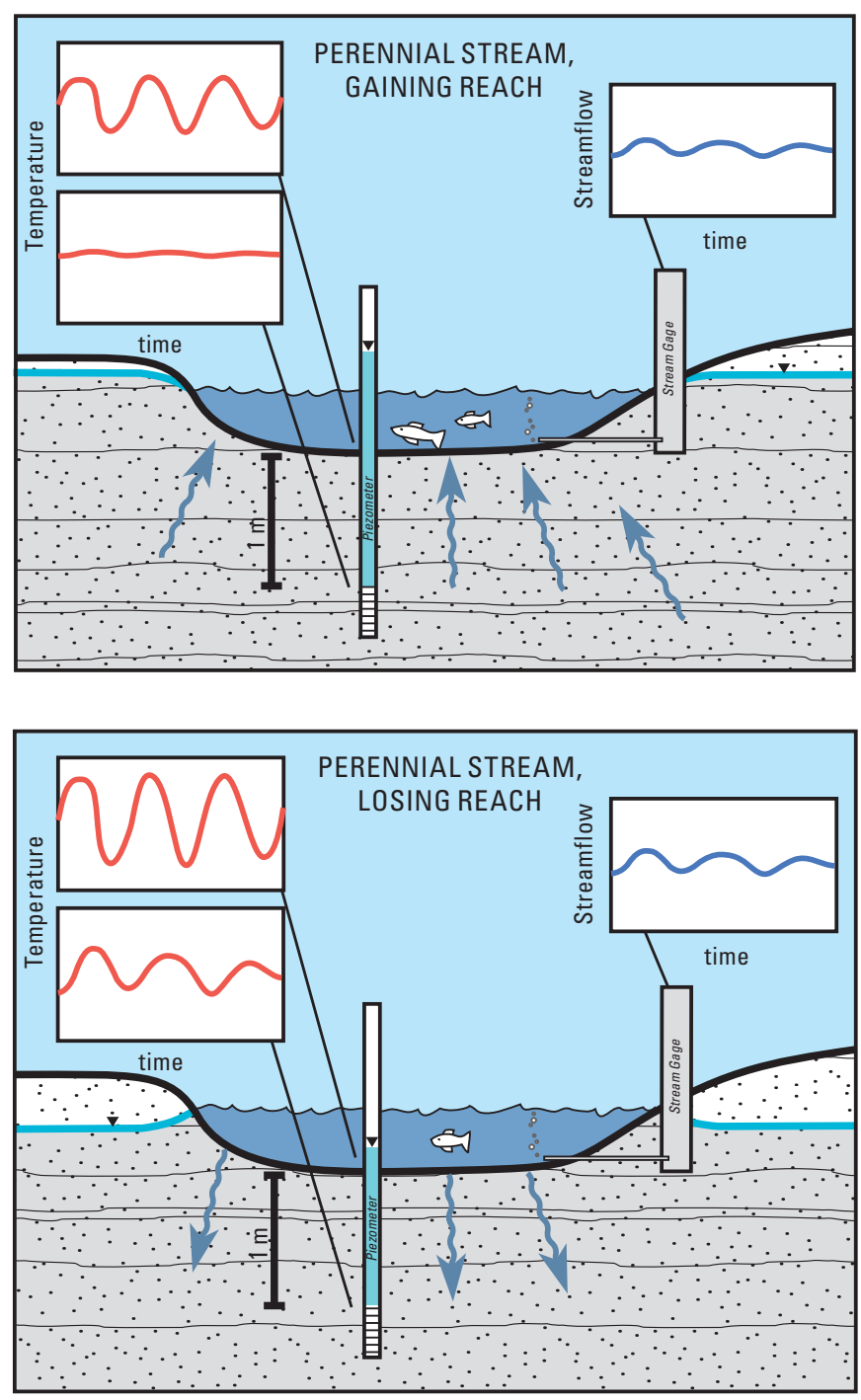

Figure 5. Idealized stream interactions with ground water, with sediment thermographs. $A$, A perennial stream gaining water from the underlying sediments. $B, A$ perennial stream losing water to the underlying sediments (modified from Constantz and Stonestrom, 2003). 


$$
P_{e}=\frac{1}{\alpha} \frac{\rho_{w} c_{w}}{\rho_{\mathrm{c}} c_{\mathrm{s}}} Q \varphi l
$$

where $l$ is the characteristic length of the medium (mean grain diameter) (L), $\alpha$ is the thermal diffusivity of the saturated soil sediments $\left(\mathrm{L}^{2} \mathrm{t}^{-1}\right), \varphi$ is the porosity $\left(\mathrm{L}^{3} \mathrm{~L}^{-3}\right)$, and $Q$ is the hydraulic flux density $\left(\mathrm{L} \mathrm{t}^{-1}\right)$. Values much less than $2 \times 10^{-4}$ indicate that heat transport is dominated by conduction (Silliman and others, 1995). Conversely, values much greater than $2 \times 10^{-4}$ indicate that heat transport is dominated by advection.

Several investigators considered the limiting case of purely advective heat transport (Nightingale, 1975; Taniguchi and Sharma, 1990; Constantz and Thomas, 1996). These studies determined water fluxes from measurements of the vertical propagation velocity of temperature fluctuations into saturated or nearly saturated sediments. Constantz and Thomas (1996) used the propagation velocity of diurnal temperature signals to estimate seepage rates beneath a strongly losing channel. Their analysis starts by expressing equation 17 as (Stallman, 1965):

$$
K_{T} \frac{\partial^{2} T}{\partial z^{2}}-Q \rho_{w} c_{w} \frac{\partial T}{\partial z}=\rho_{s} c_{s} \frac{\partial T}{\partial t}
$$

where the first term is the gain or loss of heat by conduction (the divergence of the conductive heat flux given by Fourier's first law), the second term is the gain or loss of heat by water movement (advection), and the right-hand side is the change in stored heat per unit volume of sediment per unit time. Here $Q$ is the component of the hydraulic flux density in the $z$ direction (volume of water crossing a unit area of sediment per unit time; $\mathrm{L} \mathrm{t}^{-1}$ ). If the conductive flux of heat is negligible in comparison to the advective flux of heat, equation 19 can be simplified by eliminating the first term and solving for hydraulic flux $Q$ (Constantz and Thomas, 1996):

$$
Q=\left(\rho_{s} c_{s} / \rho_{w} c_{w}\right) V_{T}
$$

where $V_{T}$ is the propagation velocity of the temperature signal $\left(\mathrm{L} \mathrm{t}^{-1}\right)$. Note that the specific heat capacity of sediment $\rho_{s} c_{s}$ in equations 19 and 20 is expressed per unit volume of bulk (wet) sediment (total bulk volume of all phases), whereas the specific heat capacity of water $\rho_{w} c_{w}$ is per unit volume of water (liquid only). Thus the term in parenthesis in equation 20 has the units of volumetric water content, making equation 20 parallel to the well-known equation relating the Darcy flux (hydraulic flux density) to the (macroscopic) propagation velocity $V_{C}$ of an ideal chemical tracer, $Q=\theta V_{C}$ (see chapter $\mathrm{E}$, this volume, for example). Here $\theta$ is the volume of water per bulk volume of sediment (water content). The propagation velocity of a chemical tracer will thus exceed that of the temperature signal by a factor of about two:

$$
V_{C} / V_{T}=(1 / \theta)\left(\rho_{s} c_{s} / \rho_{w} c_{w}\right)
$$

with parameter values typical of saturated sandy sediments $\left(\rho_{s} c_{s}=2.6 \mathrm{MJ} \mathrm{m}^{-3}{ }^{\circ} \mathrm{C}^{-1} ; \rho_{w} c_{w}=4.2 \mathrm{MJ} \mathrm{m}^{-3}{ }^{\circ} \mathrm{C}^{-1}\right.$; and $\theta=0.3$; see table 1 in Stonestrom and Blasch, 2003).

Constantz and Thomas calculated seepage losses from the arrival times of the daily temperature peak measured in the upper $3 \mathrm{~m}$ of channel sediments. Infiltration rates determined with equation 20 were about twice estimates determined from streamflow losses measured in the adjacent (upstream) reach of the channel, after correcting for evaporation. Analysis of the temperature data showed that seepage losses from intermittent streamflows were rapidly converted to deep percolation, rather than spreading laterally into near-surface storage that could later be lost to evapotranspiration.

The pure advection solution is readily applicable to multiday streamflow events with small variations in flow rate and large variations in diurnal temperature (fig. 6). Analysis becomes increasingly difficult as flow rates become more highly variable and as temperature variations at the land surface diminish. Stream segments receiving contributions from tributaries, surface runoff, and snowmelt can have erratic temperature signatures in the flowing water. As a consequence, subsurface thermographs are also erratic, making it difficult to conduct an analysis based on diurnal peaks.

\section{Numerical Techniques for Variably Saturated Flow, Multiple Layers, and Nonperiodic Forcing}

Numerical solutions to the coupled heat- and fluidtransport equations are required for most cases involving variably saturated flow, nonperiodic boundary temperatures, or non-trivial geometries. Sophocleous (1979) used a numerical model to simulate variably saturated flow of water and temperature through laboratory and field plots. Jaynes (1990) employed a similar model to evaluate the influence of layering on infiltration in agricultural soils.

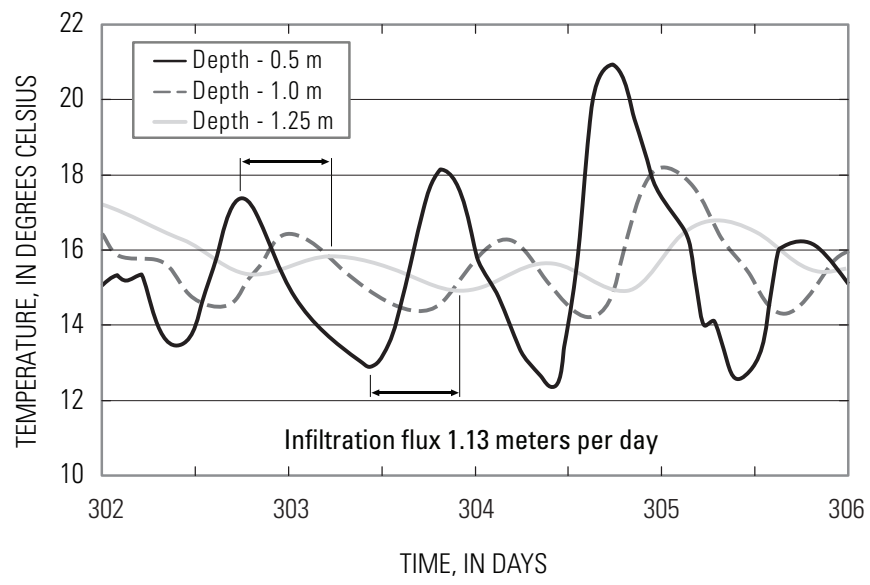

Figure 6. Example of the use of thermal amplitudes to estimate Darcy flux for predominantly advective heat transport with negligible conductive heat transport (unpublished data from Rillito Creek, Arizona). 
The ability to simulate the transport of heat has been incorporated into popular numerical models for solving problems of variably saturated water movement. Well-documented, publicly accessible examples include VS2DH (Healy and Ronan, 1996), SUTRA (Voss, 1984) and HYDRUS (Simunek and others, 1998). These models solve the Richards (1931) equation for unsaturated water movement coupled to the advection-diffusion equation for heat transport by either finitedifference or finite-element methods. Because of nonlinearities, solutions are obtained by iterative approximation. The models differ somewhat in their treatment of conduction, advection, and dispersion, and they differ considerably in their representation of thermal and hydraulic parameters. Comparing results from independently developed codes thus reduces uncertainties related to the numerical solution of governing equations.

\section{Thermal and Hydraulic Properties}

Applying thermal methods to problems of water-flux measurement requires the specification of thermal and hydraulic properties. The study of Lapham (1987) included a sensitivity analysis of stream-aquifer interactions to thermal and hydraulic properties. Thermal properties depend on the water content of the sediments, with thermal conductivity and volumetric heat capacity both increasing as soil-water content increases (fig. 7). Stonestrom and Blasch (2003) present tables of thermal conductivity, thermal diffusivity, and volumetric heat capacity for several water contents and discuss techniques for measuring and calculating thermal properties. Hydraulic properties are discussed at length in van Genuchten and others (1992).

Because the viscosity and surface tension of water both vary with temperature, hydraulic properties vary with tempera-
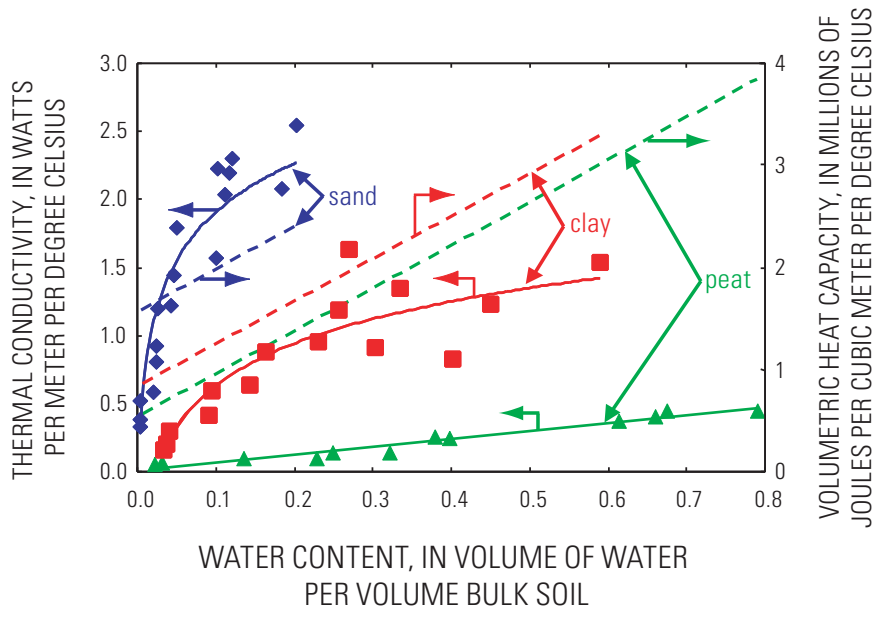

Figure 7. Dependence of volumetric heat capacity and thermal conduction on water content for selected materials. Dashed lines are volumetric heat capacities calculated as described in Stonestrom and Blasch (2003). Points are experimentally determined thermal conductivities from de Vries (1963). Solid curves are empirical fits to the thermal-conductivity data. (Modified from Stonestrom and Blasch, 2003.) ture as well. For example, hydraulic conductivity increases with increasing temperature. The dependence of hydraulic properties on temperature was investigated in the laboratory by Constantz (1982) and Nimmo and Miller (1986). These studies found that temperature dependencies of unsaturated hydraulic parameters tend to be larger than predicted by viscosity and surface tension alone. Jaynes' (1990) study of infiltration in field plots included an evaluation of temperature-dependent hydraulic conductivities on infiltration rates. Mitchell and others (1990) and Duke (1992) documented large temperature effects on infiltration fluxes in agricultural settings. Despite the greater-than-expected temperature sensitivity of hydraulic properties, the water-content dependence still dominates (van Genuchten and others, 1992).

A main reason that thermal techniques are well suited to determining water fluxes is the relative lack of dependence of thermal conductivity on sediment texture and water content relative to the large dependencies of hydraulic conductivity on these same parameters (fig. 8; Constantz and Stonestrom, 2003). Because of this, hydraulic conductivity largely controls both the percolation flux and the propagation of thermal signals in strongly advective systems (Niswonger and Prudic, 2003).

The large diurnal variations in stream temperature typical of arid and semi-arid environments strongly influence streamflow losses and associated ground-water recharge. Constantz and others (1994) showed that seepage losses from streams in Colorado and New Mexico closely tracked diurnal variations in stream temperature, with loss rates fluctuating on the order of 25 percent with daily temperature cycles that fluctuated in the range of $4-18^{\circ} \mathrm{C}$ and $10-25^{\circ} \mathrm{C}$ for Colorado and New Mexico streams, respectively. These changes were attributed to the inverse temperature dependencies of both water viscosity and water density. Both streams were located near mountain fronts. Measurements of streamflow loss and evapotranspiration at the New Mexico site indicated that 95 percent of the seepage loss became ground-water recharge. Decreased temperatures at night simultaneously reduced infiltration and extended the distal range of streamflow. Similar effects were observed in a stream in Nevada by Ronan and others (1998) and in a stream in Arizona by Blasch and others (2000). In the latter study, postflow drainage and redistribution rates increased as much as 50 percent with a change in temperature from $14^{\circ} \mathrm{C}$ to $28^{\circ} \mathrm{C}$. The temperature effects on seepage velocities were modeled using VS2DH by Ronan and others (1998), Bartolino and Niswonger (1999), and Bailey (2002). Bailey (2002) showed that seepage velocities were more sensitive to hydraulic conductivity than stage for conditions encountered in Rillito Creek, Arizona.

\section{Further Considerations for Investigation of Specific Recharge Processes}

Thermal methods offer a variety of approaches for investigating recharge processes, whether it involves infiltration at 
the land surface or percolation at depth. The following section reviews pertinent considerations for three main applications of thermal methods, the first two of which involve measurements at relatively shallow depths - the characterization of ephemeral streamflow, and the estimation of streambed seepage fluxes. The third section discusses considerations involving the application of thermal techniques to the deep unsaturated zone.

\section{Streamflow Detection}

Measuring the duration and extent of streamflow in large semiarid and arid basins is important for identifying channels that contribute to ground-water recharge. Methods employed for monitoring inputs to basin-scale and regional-scale sized recharge models need to be inexpensive and reliable. Traditional streamflow-gaging techniques are generally inapplicable because of the flashy nature of streamflow, shifting channel- geometries, the wide dynamic range of flow rates, and the potential importance of low-flow conditions. Transients in flow rates and shifting channel geometries invalidate stagedischarge relations.

Uncertainty in hydraulic conductivity versus thermal conductivity

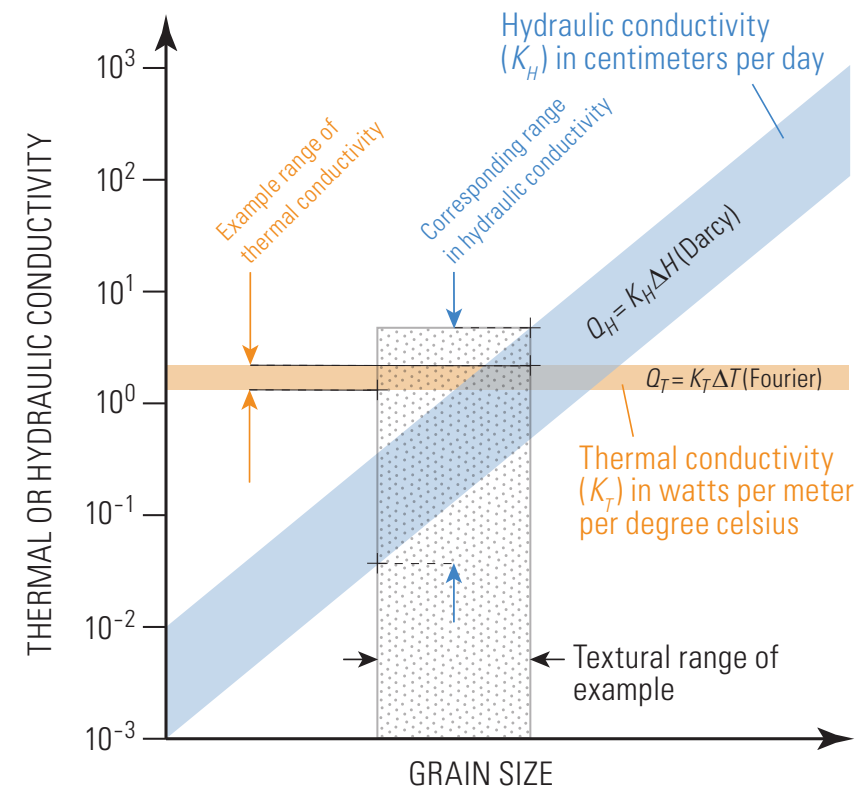

Figure 8. Uncertainty in hydraulic conductivity versus thermal conductivity. The hydraulic conductivity of saturated sediments (blue band) is strongly dependent on sediment texture (represented here by the stippled 10-90 percent range in grainsize distribution), whereas the thermal conductivity (tan band) is almost independent of texture. The vertical width of the hydraulic and thermal conductivity bands gives an approximate range of each parameter for the example texture. (From Constantz and Stonestrom, 2003).
Constantz and others (2001) used streambed temperatures to indicate the presence of streamflow in central New Mexico and southeastern Nevada. The presence of streamflow was identified with large perturbations in temperatures in the shallow subsurface due to the transport of heat by advection. Benchmark temperature measurements made at similar depths adjacent to channel helped identify false positives caused, for example, by precipitation without streamflow.

Subsequent studies of ephemerally and intermittently flowing channels in the Southwest refined methodologies of sensor placement in streambed sediments and developed automated techniques for interpreting thermographs (Lawler, 2002; Stewart, 2003; Blasch and others, 2004). Optimal placement of sensors depends on the details of flow geometry and thermal forcing as well as general meteorologic, geomorphologic, and hydrologic conditions. The following section describes optimal placement for inferring streamflow timing and extent. These considerations are largely the same as for measuring sediment temperatures to estimate percolation fluxes.

\section{Optimizing Sensor Placement}

When streamflow is not present, the thermal signal from radiant heating and cooling of the streambed sediments travels into the profile primarily by conduction (fig. 9). As this signal-idealized as a sinusoidal wave-propagates into the sediments, its amplitude decreases and its time lag increases with respect to the surface forcing (van Wijk and de Vries, 1963a). The magnitude of the ideal diurnal temperature wave as a function of depth for a homogenous single layer is (van Wijk and de Vries, 1963a):

$$
T_{\text {conduction }}(z)=T_{o} \mathrm{e}^{-z / D}
$$

where $T_{\text {conduction }}(\mathrm{z})$ is the amplitude of the sediment temperature variation at depth $z, T_{o}$ is the amplitude of the diurnal temperature wave at the sediment surface, and $D$ is the damping depth (eq. 12). The typical damping-depth value for diurnal fluctuations in sandy soils is about $0.15 \mathrm{~m}$, and in clay soils about $0.12 \mathrm{~m}$ (van Wijk and de Vries, 1963b).

When streamflow is present, the amplitude of the diurnal temperature fluctuation at the streambed surface is almost always reduced (fig. 9). During daylight hours, a portion of the thermal energy from incoming solar radiation is used to raise the temperature of the water column and to drive evaporation. The result is a lower maximum temperature at the sediment surface when streamflow is present compared to dry channel conditions. Similarly, during the evening, an overlying water column buffers the sediment surface from cool air temperatures, resulting in higher minimum temperatures than when streamflow is absent. In addition, infiltration and percolation of water through streambed sediments increases the amount of heat transported downward due to the advection of heat. As a result, thermographs at greater depths show a marked increase in the diurnal temperature amplitude in the presence of streamflow (fig. 9). 
As mentioned earlier, Stallman (1965) developed an exact analytical solution to the coupled heat- and water-transport equation for one-dimensional vertical transport in a uniform medium with a steady percolation rate and a sinusoidal temperature variation at the land surface. The diurnal temperaturewave amplitude for the advection-conduction equation 17 is (Stallman, 1965):

$$
T_{\text {advection }}(z)=T_{o} \mathrm{e}^{-a z},
$$

where $T_{\text {advection }}$ is the amplitude of the sediment temperature variation due to the combined influence of advection plus conduction, and $a(\mathrm{~L})$ is a coefficient based on the hydraulic flux density (Darcy velocity) as well as the thermal properties of the sediment:
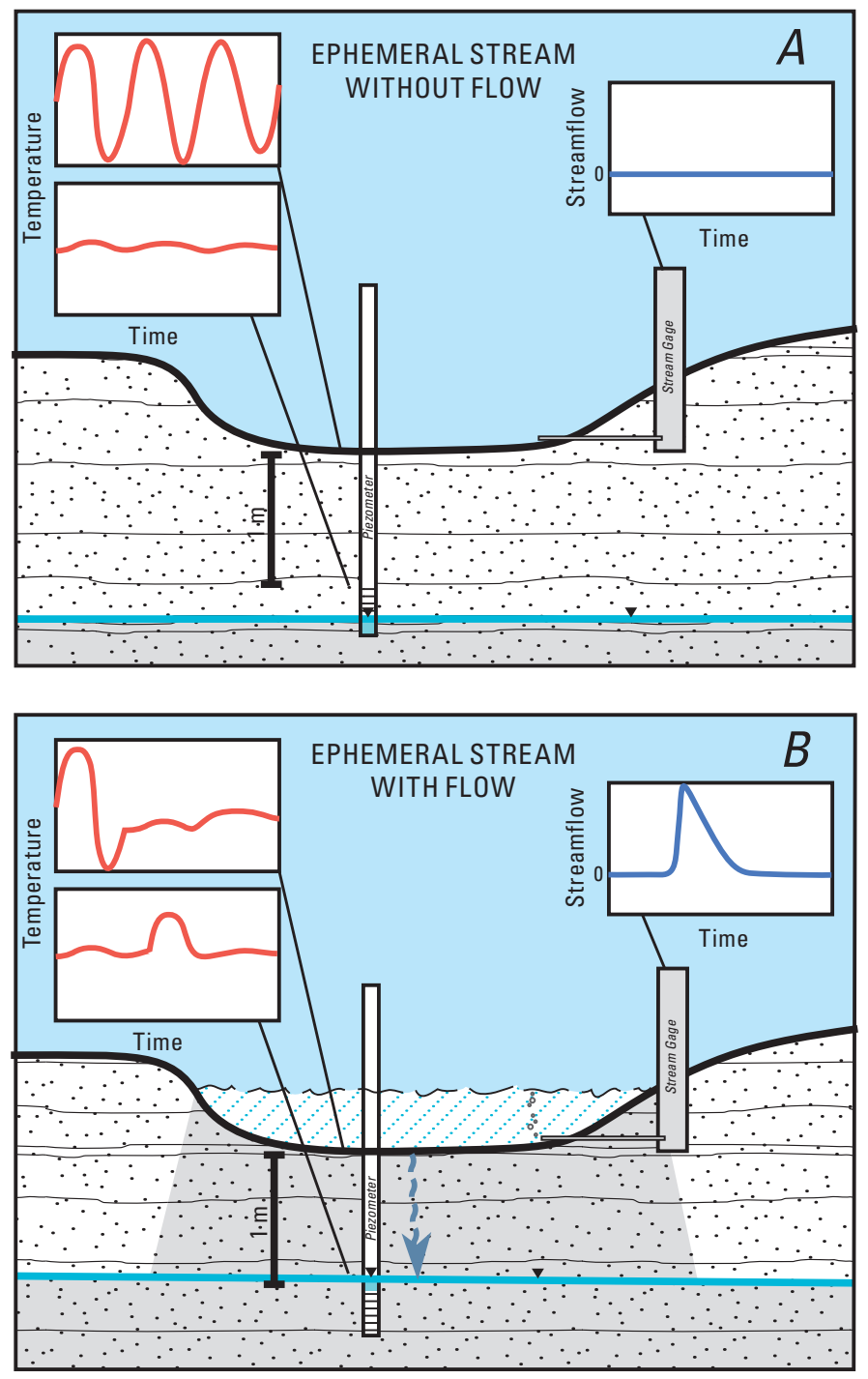

Figure 9. Streamflow hydrographs and corresponding streambed thermographs for an idealized ephemeral-stream channel $A$, before, and $B$, after onset of flow (from Constantz and Stonestrom, 2003).

$$
a=\left[\left(\beta^{2}+Q^{4} / 4\right)^{1 / 2}+\left(\beta^{2} / 2\right)\right]^{1 / 2}-Q
$$

where

$$
\beta=\frac{\pi \rho_{s} c_{s}}{\lambda P}
$$

and

$$
\lambda=\frac{Q \rho_{w} c_{w}}{2 K_{T}} .
$$

As discussed previously, the variable $c_{w}$ is the specific heat of the fluid and sediment in combination $\left(\mathrm{E} \mathrm{M}^{-1} \mathrm{~T}^{-1}\right), \rho_{s}$ is the density of the fluid and sediment in combination (M $\left.\mathrm{L}^{-3}\right), K_{T}$ is the thermal conductivity of the fluid and sediment in combination $\left(\mathrm{E} \mathrm{L}^{-1} \mathrm{t}^{-1} \mathrm{~T}^{-1}\right), Q$ is the hydraulic flux density $\left(\mathrm{L} \mathrm{t}^{-1}\right), c_{w}$ is the specific heat of pore water $\left(\mathrm{E} \mathrm{L}^{-3} \mathrm{~T}^{-1}\right)$, and $\rho_{w}$ is the density of pore water $\left(\mathrm{M} \mathrm{L}^{-3}\right)$. If $Q$ is zero, then equation 24 reduces to the conduction equation and $\beta=D^{-2}$. As $Q$ increases, the transport of heat due to advection increases. The predominant heat-transport mechanism within the sediments depends upon percolation rate, thermal parameters, and depth. For simplicity the following discussion will refer to the transport of heat during the presence of percolation as "advection" even though conduction contributes to transport of heat.

Figure 10 contrasts the purely conductive case (conduction without water movement) to the advective case (conduction with water movement). The profiles were generated using equations 22-26 with assumed hydraulic and thermal parameters for coarse-grained sediments typical of ephemeral streams. The same thermal and hydraulic properties were used in each case. Material properties were assumed to be homogeneous.

The attenuation of diurnal temperature waves are plotted as a function of depth for three different cases of streamflow in figure $10 \mathrm{~A}$. The first (no-damping) case assumes no reduction in the amplitude of diurnal temperature at the streambed surface compared to the air-sediment interface outside of the channel. The 50-percent-damping case assumes that the amplitude of the diurnal temperature signal at the streambed surface is reduced by 50 percent in the presence of streamflow. The third case assumes a 50-percent reduction in fluid flux in addition to the 50-percent water-column damping to investigate the relative importance of advective heat flux. Comparison of the conductive (no percolation) and advective (percolation) diurnal temperature waves as a function of depth shows that the conductive thermal amplitude is larger than the advective thermal amplitude, but only near the surface (fig. 10). It is also shows that percolating water transports heat deeper into the profile than conduction alone. Obviously, a requirement for using thermographs at any depth to infer streamflow is that the hydrologic flux be sufficiently large to cause measurable deviations in the amplitude of the diurnal temperature wave at that depth when streamflow is present compared to when streamflow is absent. 
To characterize depth-dependent changes in amplitude of the temperature wave resulting from percolation, the conductive temperature wave amplitude $\left(T_{\text {conducton }}\right)$ at each depth is subtracted from the advective temperature wave amplitude ( $T_{\text {advection }}$ ) (fig. 10B). When there is no reduction (damping) in the amplitude of the temperature wave at the sediment surface due flowing water in the channel, the difference in
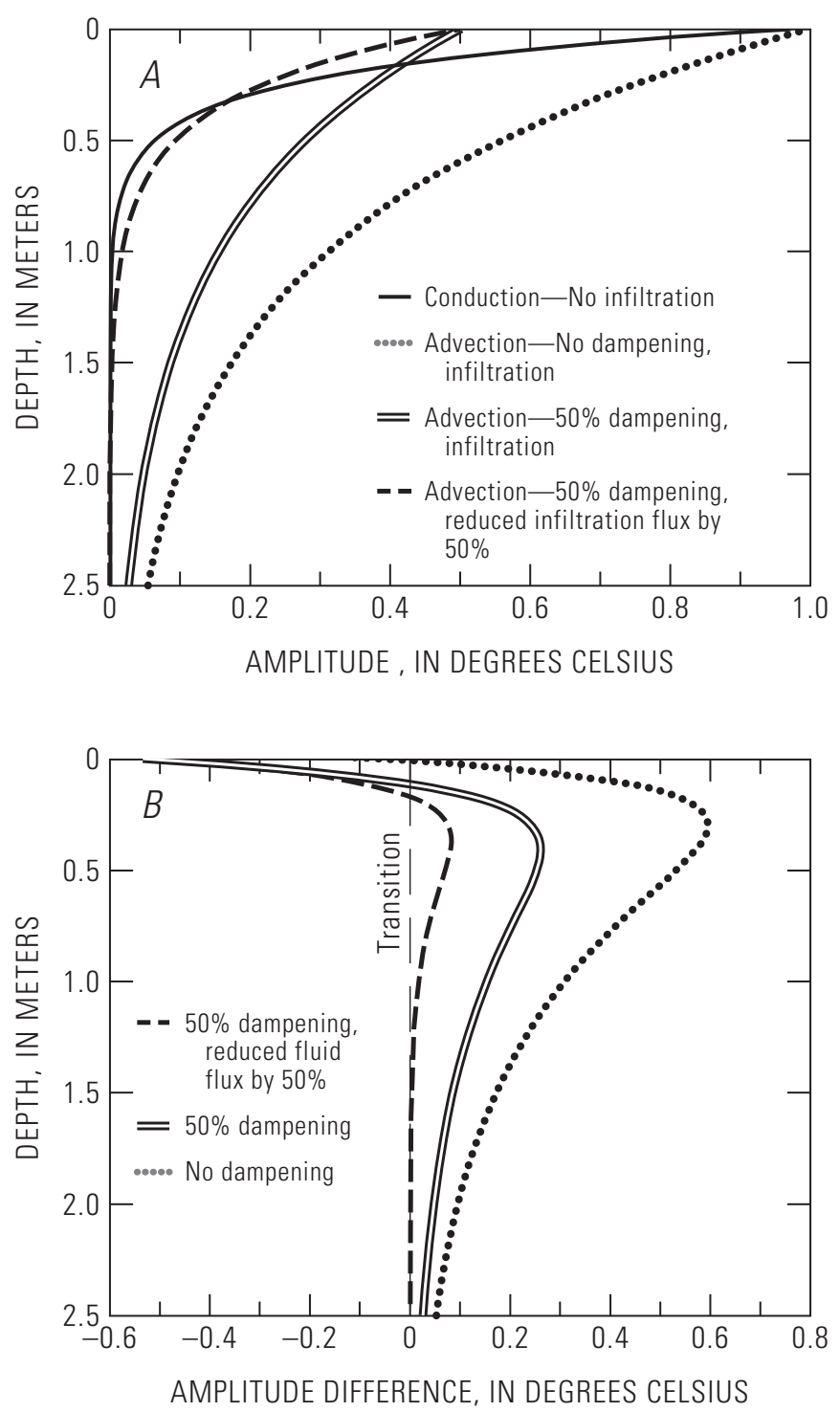

Figure 10. Amplitudes of thermal waves in a coarse-grained streambed. $A$, Conductive-only (dry channel) and advectiveplus-conductive (flowing channel) thermal-wave amplitudes (single solid line and dotted line, respectively). The amplitude at the surface is $1^{\circ} \mathrm{C}$. The 50 -percent dampening case assumes that half of the heat signal is lost to flowing water. The 50 -percent dampening-50-percent fluid-flux reduction considers in addition a fluid flux that is half of the previous two cases. $B$, Difference between advective and conductive thermal wave amplitudes as a function of depth (from Blasch and others, 2004). conductive and advective temperature-wave amplitudes at the surface is zero. At depth, however, there is a marked change between conductive and advective temperature-wave amplitudes. When the overlying water column damps the amplitude of the temperature wave at the sediment surface, there is a change in the amplitude of the temperature wave both at the surface and at depth. Thus, temperature monitoring within the profile is in general more reliable and informative than monitoring at the surface, because changes in the sign of the temperature-wave amplitude are less sensitive to possible thermal buffering by the overlying water column. This is especially true for ephemeral streams in which stage can quickly vary over a large range.

Equations 22-26 can be used with knowledge of the sediment profile and percolation range to estimate optimal measurement depths for inferring streamflow. The optimal measurement depth for inferring streamflow is that depth at which streamflow-induced percolation causes the greatest change in temperature-wave amplitude relative to no-flow conditions. For the case illustrated, the optimal depth is about $0.45 \mathrm{~m}$ (fig. 10B). The least-optimal depth is that for which the presence of streamflow does not appreciably change the temperature amplitude $\left(T_{\text {conduction }} \approx T_{\text {advection }}\right)$. For a given percolation rate, transition depths $z_{t}$ can be identified as the shallowest depth at which the conduction and advection temperature-wave amplitudes are equal with and without streamflow. The transition depth represents the depth at which the temperature-wave amplitude with flow becomes larger than the amplitude without flow.

Depths closer to the surface than $z_{t}$ may be subjected to scour or influenced by temperature anomalies induced by precipitation or cloud shadowing in the absence of flow. In extreme scour conditions, sensors can be removed entirely from the channel. Even in less extreme cases, scour and deposition complicate analysis of streambed thermographs (Constantz and others, 2001; Stewart, 2003; Gungle, 2006). Scour and fill during flow events dynamically affects the depth of the sensors below the sediment surface. This variable depth introduces uncertainty into the analysis even if sensor depths are surveyed after each flow event.

In addition to considerations just discussed, optimal depth selection for temperature sensors depends on channel cross-sectional shape, wetted perimeter, and location of adjacent vegetation and bank features. Stewart (2003) used a numerical two-dimensional model to determine the influence of cross-sectional shape on the propagation of heat both vertically and horizontally into the sediments. Rectangularshaped channels produced more transport of heat through a combination of advection and conduction than triangularshaped channels for the same constant-head upper boundary conditions. Blasch and others (2004) suggested placement of sensors in channel constrictions after observing timing errors caused by channel migration in otherwise optimal locations. Additionally, shading by vegetation, bridges, and steep banks anomalously reduced the diurnal amplitude, obscuring analysis (Lawler, 2002; Stewart, 2003). 
Constantz and others (2001) monitored temperature at the near surface $(15 \mathrm{~cm}$ depth) to successfully infer the presence of streamflow. The method was appropriate for the streams studied because two essential conditions for the success of this method were met. First, the diurnal temperaturewave amplitude at the surface was sufficiently large that temperature fluctuations caused by the passage of clouds, for example, did not obscure the diurnal signal. Second, during the presence of streamflow, the overlying water column produced a large reduction of the amplitude of the diurnal temperature wave at the streambed surface compared to the magnitude of the diurnal temperature wave in the dry streambed. The magnitudes of flow-induced perturbations can be quite large, especially for summer-monsoonal flows (fig. 11). On the other hand, changes in the near-surface diurnal temperature-wave amplitude during streamflow alone are often insufficient to infer the presence of streamflow. If antecedent pore-water temperatures in the bed sediments match temperatures in the flowing water too closely, it can become difficult to detect streamflow (Stewart, 2003).

Constantz and others (2001) and Stewart (2003) considered the effects of precipitation, cloud cover, and sudden changes in air temperature on heat transport through the bed sediments. In general, precipitation-induced fluid fluxes and abrupt air temperature changes do not penetrate as deeply below the sediment surface or as quickly as streamflow events, so will have a greater influence on sensors near the surface. Stewart (2003) compared sensors placed at 0-, 15-, 30-, 50-, and $100-\mathrm{cm}$ depths and showed that burial to $15 \mathrm{~cm}$ was sufficient to differentiate rainfall infiltration from streamflow infiltration in the cases considered.

\section{Analysis of Streamed Thermographs to Detect Presence of Streamflow}

Analysis of streambed thermographs to detect streamflow can be as simple as visual identification of streamflow-induced temperature anomalies. Although visual inspection has proven useful, the technique is subjective and is time consuming for large data sets. Also, visual inspection is less effective for identifying streamflow events shorter than 24 hours in duration, which are typical of ephemeral flows in southern Arizona (Blasch, 2003; chapters H and J, this volume). To overcome these limitations, automated techniques were developed that incorporate comparative and statistical analyses.

Benchmark measurements made outside of the flowing portion of the channel were evaluated by Stewart (2003) for automating detection of streamflow. Benchmark comparison requires that environmental conditions for the in-channel and benchmark sensors be similar. Differences caused by shading, precipitation rates, soil types, and exposure to wind can obscure interpretation (Lawler, 2002; Stewart, 2003). Benchmark methods proved less useful for short duration events than for long-term events. Data from in-channel probes during dry periods were also evaluated for their ability to provide a virtual or surrogate benchmark. Recorded diurnal oscillations and amplitudes during known dry periods were used to construct monthly and seasonal dry-benchmark signatures, which were then compared to the remaining record. However, variations caused by short-term meteorological events proved even more difficult to distinguish from streamflow events with in-channel benchmarks than with out-of-channel benchmarks (Stewart, 2003).

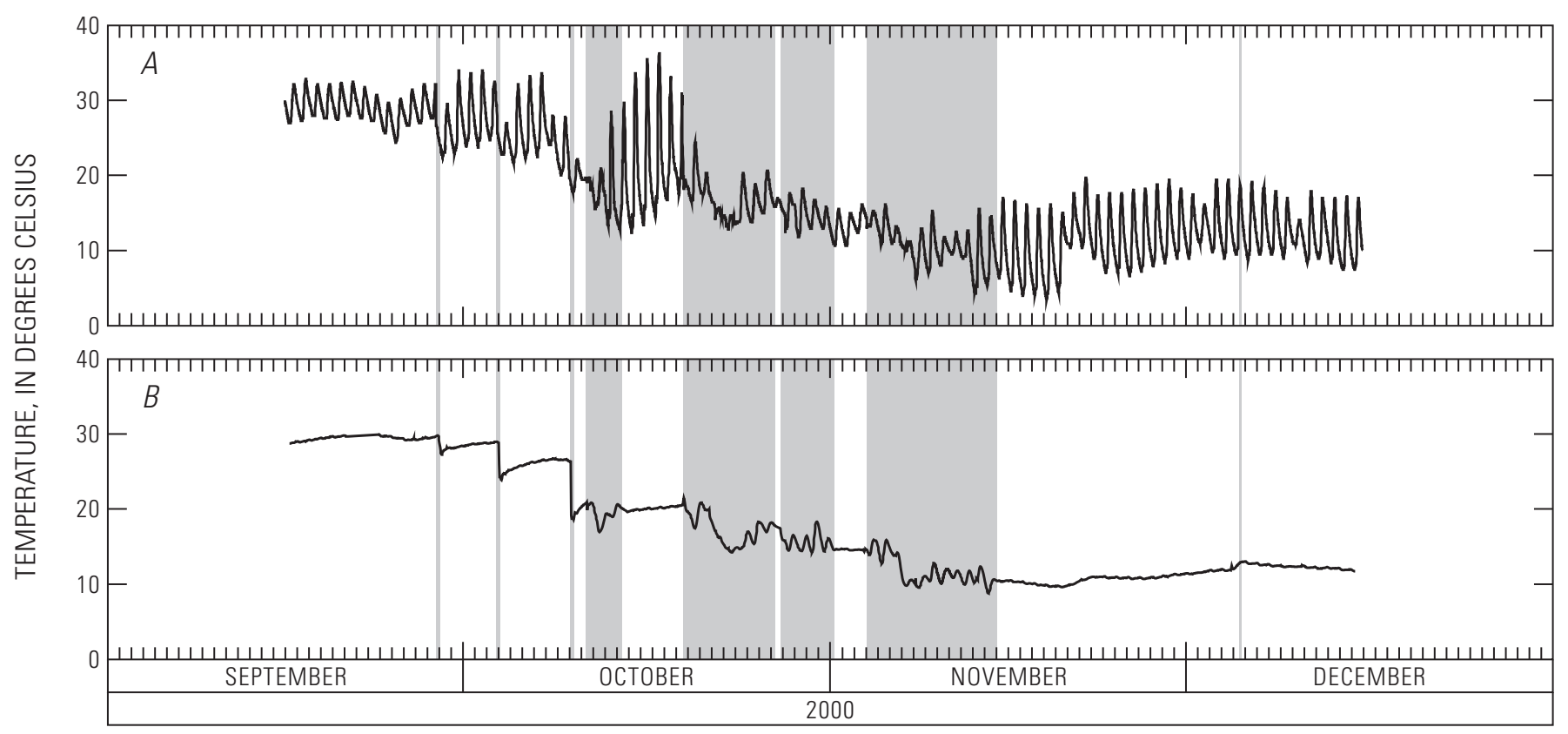

Figure 11. Thermographs for $A$, a depth above the transition depth, and $B$, a depth below the transition depth. The gray areas represent periods of streamflow (from Blasch and others, 2004). 
Analysis of a streambed thermograph to infer the timing of flow is based on identification of the aforementioned temporal changes in the thermograph (fig. 9). As an example, two thermographs for a coarse-grained alluvial stream at depths above and below the transition depth are presented in figure 11. When streamflow is present (indicated in this case from a nearby streamflow-gaging station), the diurnal temperature-wave amplitudes in the sensor above the transition depth decrease, whereas below the transition depth the diurnal amplitudes increase. Streamflow timing can be inferred from the thermographs by identifying these changes in thermal amplitude above and below the transition depth. The analysis can be conducted visually (Constantz and others, 2001) or by using statistical analysis (Stewart and Constantz, 1999; Stewart, 2003; Blasch, 2003).

Gungle (2006) reported a small but distinctive additional temperature drop in the sediments of ephemeral channels immediately after at the cessation of streamflow, which dissipated as the sediments regained the diurnal temperature pattern in effect before streamflow began (fig. 12). He attributed this brief temperature minimum to evaporative cooling of freshly exposed wet sediments. Gungle used the local temperature minimum as a marker for the cessation of streamflow. Similar observations had been previously reported by Geiger (1965) and Wierenga and others (1970).

\section{Analysis of Sensor Networks to Detect Extent of Streamflow}

The deployment of multiple sensors along a single channel or within a network of channels allows relatively inexpensive detection of the geographic extent and temporal duration of ephemeral flow events. Several examples have already been discussed (Lawler, 2002; Stewart, 2003; Gungle, 2006; chapters $\mathrm{D}-\mathrm{H}, \mathrm{J}$, and $\mathrm{K}$, this volume). Exemplifying this approach, Coes and Pool installed temperature sensors at many locations in stream channels draining the Huachuca and Mule

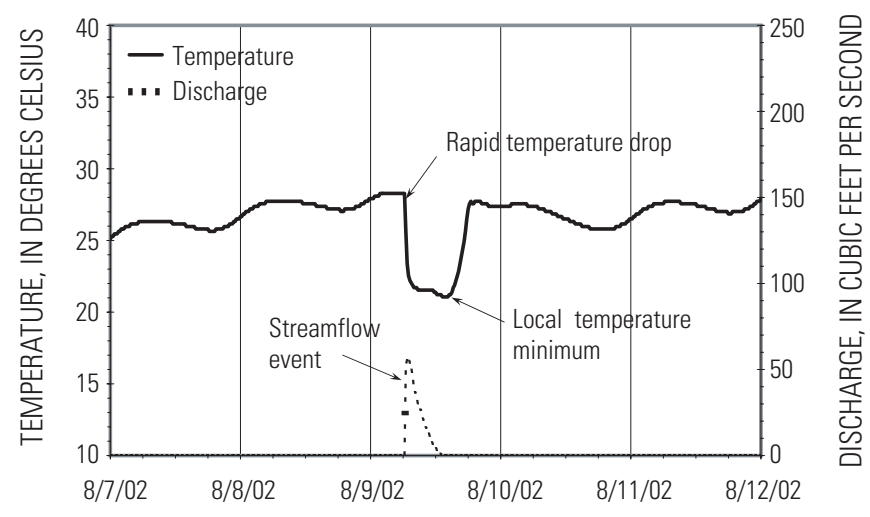

Figure 12. Thermograph and streamflow record from Greenbush Draw, southeastern Arizona, indicating the decline in temperature at the cessation of streamflow (data and interpretation from Bruce Gungle, U.S. Geological Survey, written commun., 2005).
Mountains in southeastern Arizona (chapter J, this volume). Information on the temporal and spatial extent of ephemeral streamflow was used to estimate the total mountain-front recharge for the basin.

\section{Estimation of Percolation Fluxes}

While streamflow timing alone provides qualitative information on stream-channel infiltration losses, quantifying infiltration rates and subsequent percolation fluxes and ground-water recharge amounts requires additional analysis. Of interest are not only the easily measured infiltration losses from the wetted channel but also the net (or recharging) percolation flux (infiltration minus subsequent evapotranspiration losses). Thermal methods have been widely used for estimating infiltration and percolation fluxes in small to large channels across a range of flow regimes - ephemeral, intermittent, and perennial (Constantz and Thomas, 1996; Constantz and Thomas, 1997; Ronan and others, 1998; Bartolino and Niswonger, 1999; Constantz and others, 2002; Blasch, 2003; Conlon and others, 2003).

Ronan and others (1998) developed a method to determine the vertical percolation flux beneath a streambed by solving the coupled equations for heat and water flow within the context of a publically accessible numerical model. Adaptation of the model required assigning appropriate thermal and hydraulic parameters to the bed sediments and establishing boundary conditions. As a simplification, the modeled domains were limited to fully saturated conditions, which eliminated the need to specify unsaturated parameters and the dependence of thermal and hydraulic parameters on soilwater content.

A common additional simplification is the restriction to that portion of the domain characterized by one-dimensional vertical fluxes. This restriction is often assumed to be met at all times beneath the center of the channel, and elsewhere after fully saturated conditions have been established and horizontal pressure gradients have decayed. Nevertheless, infiltration at the onset of streamflow is multidimensional, as the wetting front initially travels subhorizontally into the stream bank as well as downward. Water-content measurements in sediments of Rillito Creek at the beginning of ephemeral flow showed an initially quasi-radial progression of the wetting front, with lateral flow velocities nearly as large as vertical flow velocities (chapter $\mathrm{H}$, this volume).

\section{Instrumentation for Percolation-Flux Estimates}

Estimation of vertical fluxes requires deployment of temperature sensors at multiple depths to obtain spatial and temporal coverage (fig. 13). Stream temperatures or sedimentsurface temperatures are required to provide data on the upper boundary condition for subsequent analysis. Constantz and Thomas $(1996,1997)$ installed probes at five depths within the streambed sediments in the Middle Rio Grande Basin in 
addition to water-temperature probes at the surface. Sensors were installed directly into streambed sediments at depths of $30,60,105,150$, and $300 \mathrm{~cm}$ by auger. Temperatures were recorded every 30 minutes. Because the optimal installation depths of sensors depend on factors that are unknown a-priori, the number of depths in vertical sampling arrays is typically about five to seven. A larger number of observation depths reduces inaccuracies caused by heterogeneity and also provides insurance against the loss of data due to sensor failure or removal by scour.

Bartolino and others installed lines of nested piezometers crossing the perennial Rio Grande and manually monitored ground-water temperatures over a 24-month period (Bartolino and Niswonger, 1999; Bartolino, 2003). An advantage to using a cable-logging temperature sensor was the ability to obtain high spatial resolution. Measurements were obtained at $15-\mathrm{cm}$ intervals for piezometers about 9-16 meters in depth. An assumption of this method is that the water temperature inside the piezometers equaled the temperature of saturated sediments outside the piezometers.

Bailey (2002) and Coes and Pool (chapter J, this volume) applied a similar approach to the unsaturated zone beneath an ephemeral stream prone to scour and deposition. Piezometers were installed about $10 \mathrm{~m}$ into the bed sediments, and an array of self-contained temperature sensors was mounted on a cable and inserted into the piezometers. The temperature sensors included self-contained data loggers. This system enabled continuous data collection within the sediments and ready access to probes without having to repeatedly disturb the sediments. Temperatures inside the borehole were assumed to be equal to temperatures outside the borehole.

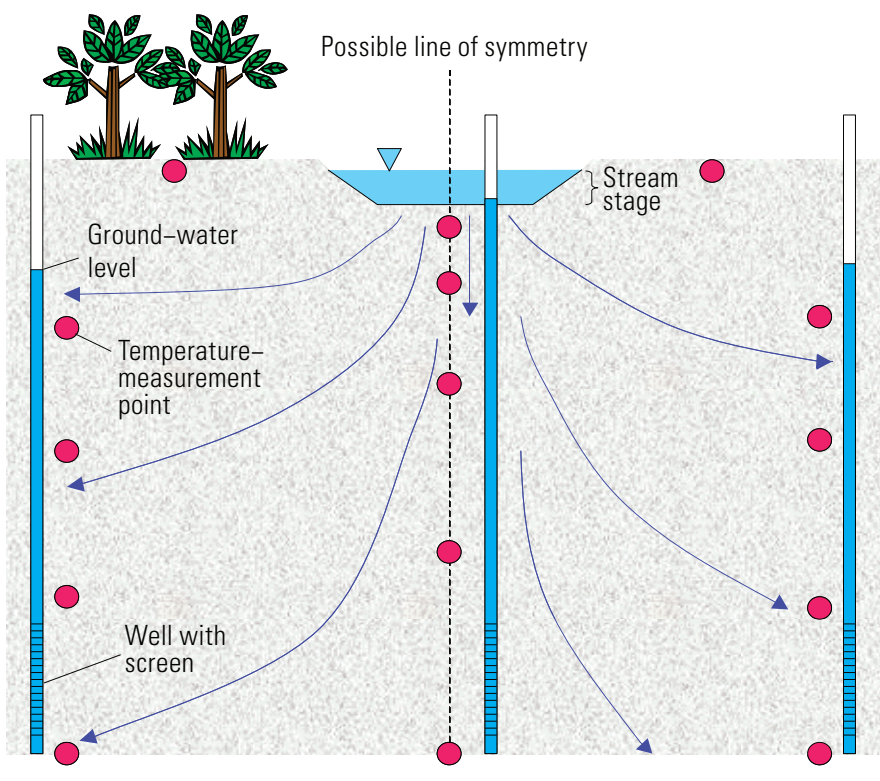

Figure 13. Conceptual modeling framework when flow through streambed is downward and outward (from Niswonger and Prudic, 2003.)
To investigate installation considerations related to the assumption of vertical fluxes, Ronan and others (1998) deployed two-dimensional arrays of temperature sensors beneath an ephemeral stream and used thermal modeling techniques to estimate two-dimensional infiltration and percolation fluxes. The authors observed vertical and lateral flow variations within the sediments due to layering as well as to the geometry of channel meandering relative to hillslope direction. As previously discussed, Stewart (2003) simulated two-dimensional flow in a rectangular channel bottom and a triangular channel bottom. Flow was predominantly vertical beneath most of the width of the rectangular channel, with lateral components of flow increasing near the edges of channel flow. The same pattern was observed beneath the triangular channel. Comparison of the two channel geometries indicated a greater proportion of vertical flow beneath the rectangular channel than beneath the triangular channel for a given head or wetted channel cross-sectional area.

\section{Hydraulic and Energy Transport Properties}

Hydraulic parameters required for numerical modeling of saturated conditions include hydraulic conductivity (a tensor for anisotropic materials), specific storage, and porosity, whereas modeling unsaturated conditions requires additional parametric functions describing soil-moisture retentivity and unsaturated hydraulic conductivity. Required thermal-transport parameters include heat capacity and thermal conductivity of the sediment, both as functions of water content, as well as thermal dispersivity. Hydraulic and energy-transport parameters can be determined from core samples (Bailey, 2002; chapter J, this volume), literature values (Bartolino and Niswonger, 1999), expert judgment (Ronan and others, 1998), or model calibration (Bartolino and Niswonger, 1999). Often a combination of methods is used to obtain the full set of required parameters.

Sensitivity analysis has shown that hydraulic conductivity is the most important parameter controlling infiltration flux (Smith and others, 1989; Wang and others, 1989; Ronan and others, 1998; Bartolino and Niswonger, 1999). Inverse calibration using automated procedures, such as PEST (Doherty and others, 1994) and UCODE (Poeter and Hill, 1998) have become routine in channel-recharge investigations (Bartolino and Niswonger, 1999; Bailey 2002; Stewart, 2003; Constantz and others, 2003). Niswonger and Prudic (2003) provide guidance on the application of inverse calibration for thermal studies of surface-water-ground-water interactions.

\section{Boundary and Initial Conditions}

Infiltration and associated percolation fluxes largely depend on the product of the hydraulic gradient and the hydraulic conductivity of the sediments. Temperature data alone can be insufficient to determine both hydraulic conductivity and water fluxes through inverse modeling procedures. 
Solutions become better constrained with the consideration of additional types of data. Pressure observations are the most commonly used auxiliary data for constraining solutions of the coupled transport equations. Piezometers (often outfitted with recording transducers) can be used to measure pressure gradients in saturated sediments. Similarly, tensiometers can be used in unsaturated sediments. Measurement of matric pressure or water content is often required to obtain the required parameters for partially saturated conditions. At a minimum, hydraulic — as well as thermal_-initial and boundary conditions must be specified to run the transport model.

The measured depth of water in the stream channel, if available, is usually used as the upper hydraulic boundary condition (Ronan and others, 1998; Bailey, 2002). As discussed above, Bartolino and Niswonger (1999) employed rows of piezometers to study surface-water-ground-water exchanges along the Rio Grande. Hoffmann and others (chapter $\mathrm{H}$, this volume) used subsurface pressure sensors to measure hydraulic head during ephemeral flow of Rillito Creek.

The bottom boundary condition can be represented in several ways. The bottom boundary is often represented as a zero-pressure head boundary corresponding to the measured or assumed location of the water table (Ronan and others, 1998; Bailey, 2002). Another option is the use of measured pressure heads at the bottom of the model domain (Bartolino and Niswonger, 1999). Alternative approaches are to place the lower boundary at a great enough distance from the active domain that assumed stationary conditions do not affect the active domain, or to assume constant vertical gradients of temperature and pressure at depth. The latter two approaches simulate percolation as occurring into a semi-infinite half-space.

Initial conditions include pressure-head and temperature profiles in the sediments. For unsaturated media, initial water-content conditions have been determined directly from core samples (Ronan and others, 1998). Initial water-content conditions can also be determined from time-domain-reflectometry measurements (Blasch, 2003; appendix 2, this volume).

\section{Sensitivity of Fluxes to Hydraulic Conductivity}

Since modeled fluxes reflect hydraulic gradient and hydraulic conductivity, solutions are sensitive to fluctuations in stream stage and hydraulic conductivity. While stream stage can be measured independently, changes in hydraulic conductivity over the course of an ephemeral flow event can be difficult to monitor. Bailey (2002) estimated infiltration rates along Rillito Creek by using temperature monitoring and inverse simulation of heat and water transport through stream sediments. Modeling of two sequential streamflow events suggested that the hydraulic conductivity of the streambed surface layer changed by four orders of magnitude due to sediment redistribution from one event to the next. During a single event, the hydraulic conductivity changed by two orders of magnitude.

The data of Ronan and others (1998) showed generally decreasing infiltration rates throughout the duration of a multiple-day ephemeral flow event with superimposed diurnal oscillations, representing the net effect of several influences. The dominant influence was the rapid decrease in hydraulic gradient at the sediment-water column interface as infiltration proceeds. An opposing influence was the initial increase of hydraulic conductivity as water content increases from preflow to saturated conditions. Hydraulic conductivity fluctuated diurnally with fluctuating streamflow temperature.

Blasch and others (2006) simulated transient infiltration fluxes at the onset of the streamflow events by using measured field data from alluvial channels (fig. 14). The multiple transient and steady-state fluxes observed after the onset of streamflow were attributed to the layering of streambed sediments. The time between transient and steady-state periods was inversely proportional to the antecedent moisture content. The results of Coes and Pool (chapter J, this volume) indicated that even their longest recorded streamflow event, $5.5 \mathrm{hrs}$, was not long enough for infiltration to reach steady state.

\section{Accuracy of Infiltration and Percolation Fluxes}

Infiltration and percolation fluxes calculated from thermal monitoring and numerical models have been compared to fluxes calculated by using data from streamflow-gaging stations, stage recorders, chemical tracers, and soil-water content measurements. Constantz and Thomas (1996) estimated a factor-of-two difference between vertical fluxes calculated by using a thermal method and fluxes calculated from streamflow data. Ronan and others (1998) reported simulated infiltration rates that were within an order of magnitude of seepage rates determined from flume data. The difference was partially attributed to the difference in the point-scale measurements of the thermal method and reach-scale measurements of the seepage runs. To evaluate the accuracy of simple heat-based flux estimates, Blasch and others (2006) compared thermallydetermined infiltration fluxes near the onset of streamflow with continuously monitored soil-water content data. Because initial transient rates are higher than eventual quasi-steady state rates, errors in cumulative infiltration caused by considering only the quasi-steady behavior ranged from 9 to 25 percent for the cases tested. Cumulative error for more typical, shortduration (8-hour) events was about 90 percent.

Niswonger and Prudic (2003) provide guidance for collecting field data and modeling measured temperatures to infer hydraulic fluxes. These procedures are designed to broaden the applicability of thermal methods while reducing measurement uncertainty.

\section{Thermal Methods for Quantifying Deeper Recharge}

Focused recharge occurs at discreet locations, such as stream channels, whereas diffuse recharge is spread over the landscape. Percolating water generally becomes more diffuse with depth (Nimmo and others, 2002); however, focused recharge in arid settings can reach great depths. This is par- 

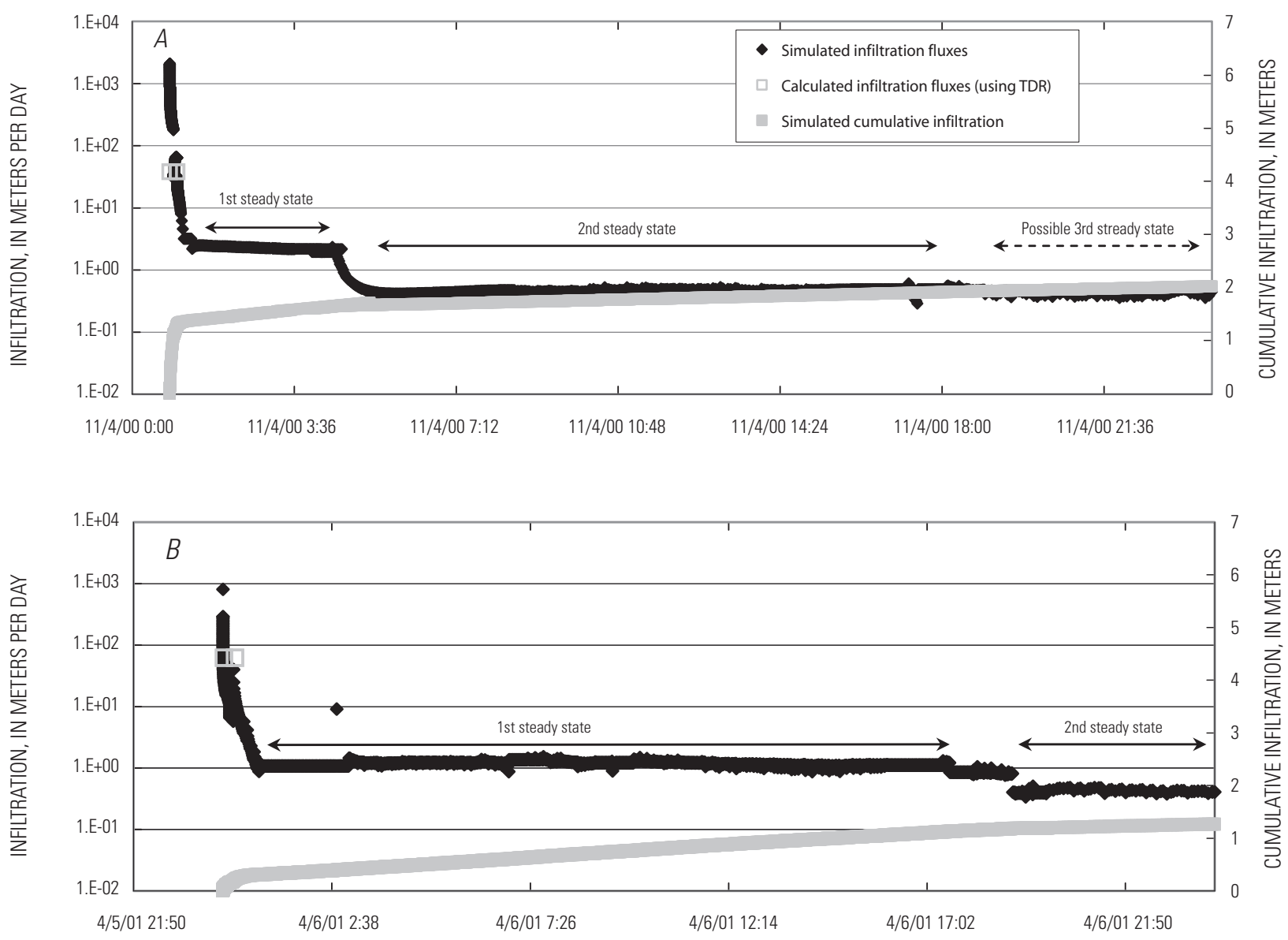

Figure 14. Simulated infiltration fluxes and cumulative infiltration for $A$, November 4, 2000 and $B$, April 6, 2001. Infiltration fluxes at the onset of streamflow were calculated by using time-domain reflectometry (TDR) water-content measurements (from Blasch and others, 2006).

ticularly true for large volume, spatially discreet inputs, such as those that occur within large ephemeral streams, and areas that receive large volumes of artificial recharge from irrigation (Stonestrom and others, 2004) and percolation ponds (Izbicki and others, chapter G, this volume). Nimmo and others (2005) provide an overview of thermal methods for the investigation of deeper recharge.

A comparison of thermal methods to track shallow, moderate, and deep percolating water on progressively slower paths toward recharge was presented by Constantz and others (2003). Temperature-estimated fluxes were as large as $20 \mathrm{~m} / \mathrm{d}$ for shallow depths immediately beneath a stream channel and as small as $0.01 \mathrm{~m} / \mathrm{d}$ for depths greater than $100 \mathrm{~m}$ below the surface beneath an alluvial fan. A trend to smaller fluxes with increasing depth was partly explained by the spreading of downward percolating moisture with depth, although deep percolation rates may reflect arrested paleorecharge (Walvoord and others, 2004). In any case, flux divergence beneath focused sources of water due to sediment layering generates additional attenuation of thermal signals beyond the amount expected in homogeneous sediments. The greater the depth of the recharge investigation, the greater the need for precision in temperature measurements. A precision of $0.1^{\circ} \mathrm{C}$ is usually more than adequate for estimating fluxes near the land surface, whereas a precision of at least $0.01^{\circ} \mathrm{C}$ is required to detect thermal perturbations at depths greater than a few tens of meters.

Studies that used thermal data to examine recharge in moderate-to-deep unsaturated zones include those of Reiter (1999, 2001), Izbicki and Michel (2002), Constantz and others (2003), and Dowman and others (2003). Examining unsaturated zones to depths of $100 \mathrm{~m}$ and saturated zones to depths of $350 \mathrm{~m}$, Reiter used high-precision temperature logs to evaluate vertical moisture fluxes in the Rio Grande Rift in central and southern New Mexico. Thermal gradients were measured with precisions of $0.005^{\circ} \mathrm{C} / \mathrm{m}$. Vertical water fluxes as low at $1 \times 10^{-6} \mathrm{~m} / \mathrm{yr}$ were obtained by fitting quadric and cubic polynomials to measured temperature data and matching analytical solutions.

Izbicki and Michel (2002) used temperature profiles to depths of $30 \mathrm{~m}$ for estimating recharge rates and cumulative recharge volumes beneath ephemeral and intermittent streams across the western Mojave Desert. Air temperatures were monitored in cased and grouted boreholes in normally dry 
washes to estimate the sediment-temperature profiles. Companion boreholes outside the channel were used for no-flow controls. Average annual temperatures beneath the washes were as much as $1.5^{\circ} \mathrm{C}$ lower than the average temperatures for the control sites. Assuming one-dimensional heat transport by conduction and advection, calculated recharging fluxes from intermittent runoff ranged from 0.22 to $0.84 \mathrm{~m} / \mathrm{yr}$ depending on distance downstream from the mountain front.

In the study alluded to above, Constantz and others (2003) used thermal geophysical logs from boreholes as deep as $300 \mathrm{~m}$ to estimate recharge in southern Nevada beneath an alluvial-fan surface. Recharging fluxes were estimated from perturbations of assumed geothermal profiles on the basis of analytical solutions to the coupled heat-and-water flow equations as well as numerical solutions generated by TOUGH2 (Preuss and others, 1999). Estimates of recharging fluxes ranged from undetectable to $0.011 \mathrm{~m} / \mathrm{yr}$.

Dowman and others (2003) investigated temperature perturbations beneath Rillito Creek during constant-flux streambed infiltration experiments. A 5-m by 5-m bermed area was instrumented with buried thermocouples to a depth of $5 \mathrm{~m}$, and a $15 \mathrm{~m}$-borehole adjacent to the buried area was logged for temperature using a cable-mounted logging thermistor. Temperatures measured by the buried sensors agreed with borehole temperatures at depths greater than about $1 \mathrm{~m}$. An imposed percolation flux of $0.34 \mathrm{~m} / \mathrm{d}$ produced a thermal anomaly that reached $11^{\circ} \mathrm{C}$ of cooling at shallow depth (above the transition point) and $0-2^{\circ} \mathrm{C}$ of heating between 4 and $10 \mathrm{~m}$ depth (below the transition point). Numerical sensitivity analysis using VS2DH showed that the temperature of the percolating water and percolation rate were the most important factors in determining the temperature-profile perturbation. The analysis also showed that having the deeper temperature measurements substantially reduced the uncertainty of recharge-rate estimates compared to estimates that were based on shallow temperature measurements alone.

\section{Conclusions}

Thermal methods have emerged as a versatile class of geophysical tools for monitoring focused recharge in arid and semiarid settings. Compared to other geophysical techniques and chemical tracers, thermal methods are relatively simple and inexpensive. Heat flows through hydrologic systems naturally. Heat can also be artificially introduced and is benign over a useful range of applications. The theory for coupled heat-and-water transport is well established and incorporated into numerical models of variably saturated flow.

Recent investigations have led to improved methods for experimental design and data collection. Instrumentation has been steadily improving. Additionally, the treatment of unsaturated thermal- and hydraulic-transport processes through numerical models provides flexibility not possible 50 years ago, when Suzuki first estimated percolation rates beneath a field of rice (Suzuki, 1960).
Like other methods for determining recharge rate, thermal techniques are limited by sampling accessibility and scale of measurement, which often become limiting factors in recharge investigations. Nevertheless, thermal methods are particularly well suited for monitoring focused recharge beneath unconsolidated alluvial channels that remain dry much of the time.

The coupled relation between heat and water transport has been used to identify the occurrence, extent, and timing of streamflow. Temperature measurements have also been used to indicate gaining and losing reaches of stream channels as well as of areas of inflow to lakes. Temperature observations beneath the depth of seasonal fluctuations have been used to identify the presence and direction of water movement through analyses of anomalies in the background geothermal gradient.

Infiltration and percolation estimates determined by thermal techniques are similar to values determined by channelflow-loss measurements and chemical tracers. In addition, thermal techniques provide the ability to continuously monitor infiltration and percolation fluxes throughout streamflow events. Thermal studies have shown that infiltration rates can vary by four orders of magnitude from the onset to late stages of ephemeral streamflow not only because of hydraulicgradient decay, but also because of flow-induced changes in the hydraulic conductivity of streambed sediments. Fluxes as high as $100 \mathrm{~m} / \mathrm{d}$ have been detected in coarse alluvial sediments, whereas fluxes as low as $0.01 \mathrm{~m} / \mathrm{d}$ have been detected in clayey sediments.

Thermal methods have been used to estimate groundwater recharge rates hundreds of meters beneath stream channels and basin floors. Lateral spreading of percolating water often reduces local vertical-flux densities to values substantially lower than those prevailing near the surface. Estimated fluxes at depths exceeding $100 \mathrm{~m}$ determined by thermal methods range from $0-0.01 \mathrm{~m} / \mathrm{d}$. Detecting small fluxes at such great depths requires extraordinary precision. Measurement depth is, therefore, a major consideration when applying thermal methods to estimate recharge in arid environments.

\section{References Cited}

Bailey, M.A., 2002, Analysis of one-dimensional vertical infiltration using heat as a tracer in Rillito Creek, Tucson, Arizona: Tucson, University of Arizona, masters thesis, $152 \mathrm{p}$.

Bartolino, J.R., 2003, The Rio Grande-Competing demands for a desert river, in Stonestrom, D.A., and Constantz, J., eds., Heat as a tool for studying the movement of ground water near streams: U.S. Geological Survey Circular 1260, p. 7-16.

Bartolino, J.R., and Niswonger, R.G., 1999, Numerical simulation of vertical ground-water flux of the Rio Grande from ground-water temperature profiles, central New Mexico: U.S. Geological Survey Water-Resources Investigations Report 99-4212, 34 p. 
Beck, A.E., Garven, G., and Stegena, L., eds., 1989, Hydrogeological regimes and their subsurface thermal effects: American Geophysical Union, Geophysical Monograph, v. 47, $158 \mathrm{p}$.

Blasch, K.W., 2003, Streamflow timing and estimation of infiltration rates in ephemeral stream channels using variably saturated heat and fluid transport methods: Tucson, University of Arizona, Ph.D. dissertation, 204 p.

Blasch, K.W., Ferré, P.A., and Hoffmann, J.P., 2004, A statistical technique for interpreting streamflow timing using streambed sediment thermographs: Vadose Zone Journal, v. 3, p. 936-946.

Blasch, K.W., Ferré, T.P.A., Hoffmann, J.P., and Fleming, J.B., 2006, Relative contributions of transient and steady state infiltration during ephemeral streamflow: Water Resources Research, v. 42, no. 8, doi:10.1029/2005WR004049.

Blasch, K.W., Fleming, J.B., Hoffmann, J.P, and Ferré, P.A., 2000, Temperature and moisture content profiling of an ephemeral stream channel in a semiarid watershedComparison of vertical infiltration velocities at the onset and cessation of flow [abs.]: Eos (American Geophysical Union Transactions), Fall Meeting Supplement, v. 81, no. 48, p. F502.

Boyle, J.M., and Saleem, Z.A., 1979, Determination of recharge rates using temperature depth profiles in wells: Water Resources Research, v. 15, no. 6, p. 1616-1622.

Bullard, E.C., 1939, Heat flow in South Africa: Proceedings of the Royal Society of London A, v. 173, p. 474-502.

Bredehoeft, J.D., and Papadopulos, I.S., 1965, Rates of vertical groundwater movement estimated from the Earth's thermal profile: Water Resources Research, v. 1, no. 2, p. $325-328$.

Carslaw, H.S., and Jaeger, J.C., 1959, Conduction of heat in solids ( $2 \mathrm{~d}$ ed.): New York, Oxford University Press, 510 p.

Cartwright, K., 1970, Groundwater discharge in the Illinois Basin as suggested by temperature anomalies: Water Resources Research, v. 6, no. 3, p. 912-918.

Cartwright, K., 1979, Measurement of fluid velocity using temperature profiles - experimental verification: Journal of Hydrology, v. 43, p. 185-194.

Conlon, T., Lee, K., and Risley, J., 2003, Heat tracing in streams in the Central Willamette Basin, Oregon, in Stonestrom, D.A., and Constantz, J., eds., Heat as a tool for studying the movement of ground water near streams: U.S. Geological Survey Circular 1260, p. 29-34.

Constantz, J., 1982, Temperature dependence of unsaturated hydraulic conductivity of two soils: Soil Science Society of America Journal, v. 46, p. 466-470.
Constantz, J., 1998, Interaction between stream temperature, streamflow, and groundwater exchanges in alpine streams: Water Resources Research, v. 34, no.7, p. 1609-1615.

Constantz, J., Stewart, A.E., Niswonger, R., and Sarma, L., 2002, Analysis of temperature profiles for investigating stream losses beneath ephemeral channels: Water Resources Research, v. 38, no. 12, p. 51-2 to 51-13.

Constantz, J., and Stonestrom, D.A., 2003, Heat as a tracer of water movement near streams, in Stonestrom, D.A., and Constantz, J., eds., Heat as a tool for studying the movement of ground water near streams: U.S. Geological Survey Circular 1260, p. 1-6.

Constantz, J., Stonestrom, D., Stewart, A.E., Niswonger, R., and Smith, T.R., 2001, Analysis of streambed temperature in ephemeral stream channels to determine streamflow frequency and duration: Water Resources Research, v. 37, no. 2, p. 317-328.

Constantz, J., and Thomas, C.L., 1996, The use of streambed temperature profiles to estimate depth, duration, and rate of percolation beneath arroyos: Water Resources Research v. 32, no. 12 , p. 3597-3602.

Constantz, J., and Thomas, C.L., 1997, Streambed temperature profiles as indicators of percolation characteristics beneath arroyos in the Middle Rio Grande Basin, USA: Hydrologic Processes, v. 11, p. 1621-1634.

Constantz, J., Thomas, C.L., and Zellweger, G., 1994, Influence of diurnal variations in stream temperature on streamflow loss and groundwater recharge: Water Resources Research, v. 30, no.12, p. 3253-3264.

Constantz, J., Tyler, S.W., and Kwicklis, E., 2003, Temperature-profile methods for estimating percolation rates in arid environments: Vadose Zone Journal, v. 2, p. 12-24.

Darcy, H., 1856, Les fontaines publiques de la ville de Dijon: Paris, Victor Dalmont, 647 p.

Day-Lewis, F.D., Karam, H.N., Harvey, C.F., Lane, J.W., 2006, Monitoring submarine ground-water discharge using a distributed temperature sensor, Waquoit Bay, Massachusetts [abs.]: Eos (American Geophysical Union Transactions), v. 87, no. 52, NS24A-02.

de Vries, D.A., 1963, Thermal properties of soils, in van Wijk, W.R., ed., Physics of plant environment ( $2 \mathrm{~d}$ ed.): Amsterdam, North-Holland Publishing Co., p. 210-235.

Doherty, J., Brebber, L., and Whyte, P., 1994, PEST-Model independent parameters estimation: Brisbane, Australia, Watermark Computing, 160 p.

Dowman, C.E., Ferre, T.P.A., Hoffmann, J.P., Rucker, D.F., and Callegary, J.B., 2003, Quantifying ephemeral streambed infiltration from downhole temperature measurements collected before and after streamflow: Vadose Zone Journal, v. 2, p. 595-601. 
Duke, H.R., 1992, Water temperature fluctuations and effect on irrigation infiltration: Transactions of the American Society of Agricultural Engineers, v. 35, no. 1.

Freeze, R.A., and Cherry, J.A., 1979, Groundwater: Englewood Cliffs, N.J., Prentice-Hall, p. 25-26.

Geiger, R., 1965, The climate near the ground: Cambridge, Mass., Harvard University Press, 611 p.

Gungle, B., 2006, Timing and duration of flow in ephemeral streams of the Sierra Vista subwatershed of the Upper San Pedro River Basin, Cochise County, southeast Arizona: U.S. Geological Survey Scientific Investigations Report 2005-5190, 47 p.

Gungle, B., 2007, Investigation of ground-water/surfacewater interactions in the San Pedro River near Charleston using fiber-optic distributed temperature methods [abs.], in Sustainable water, unlimited growth, quality of life: Can we have it all?, Arizona Hydrological Society, Proceedings of the 20th Annual Symposium, August 29-September 1, 2007, Tucson, Arizona [electronic medium).

Healy, R.W., and Ronan, A.D., 1996, Documentation of computer program VS2DH for simulation of energy transport in variably saturated porous media-Modification of the U.S. Geological Survey computer program VS2DT: U.S. Geological Survey Water-Resources Investigations Report 96-4230, 36 p.

Heath, R.C., 1964, Seasonal temperature fluctuations in surficial sand near Albany, New York: U.S. Geological Survey Professional Paper 475-D, p. D204-D208.

Hoekstra, P., and Miller, R.D., 1967, On the mobility of water molecules in the transition layer between ice and a solid surface: Journal of Colloid Interface Science, v. 25, p.166-173.

Izbicki, J.A., and Michel, R.L., 2002, Use of temperature data to estimate infiltration from intermittent streams in the western Mojave Desert, USA, in Foo, D.Y., ed., Balancing the ground water budget, Proceedings of the International Association of Hydrogeologists Meeting in Darwin, Australia, May 12-14, 2002 [CD-ROM): Kenilworth, UK, IAH, 9 p.

Jaynes, D.B., 1990, Temperature variation effects on field measured infiltration: Soil Science Society of America Journal, v. 54, no. 2, p. 305-312.

Kipp, K.L., 1987, HST3D—A computer code for simulation of heat and solute transport in three-dimensional ground-water flow systems: U.S. Geological Survey WaterResources Investigations Report 86-4095, 517 p.

Lachenbruch, A.H., and Sass, J.H., 1977, Heat flow in the United States and the thermal regime of the crust, in Heacock, J.G., ed., The Earth's crust: American Geophysical Union, Geophysical Monograph 20, p. 626-675.
Lapham, W.W., 1987, Use of temperature profiles beneath streams to determine rates of vertical ground-water flow and vertical hydraulic conductivity: U.S. Geological Survey Water Supply Paper 2337, 35 p.

Lawler, David, 2002, Using streambed temperature sensors to monitor flow events in the San Pedro River, southeastern Arizona, and north-central Sonora, Mexico: Tucson, University of Arizona, M.S. thesis, 68 p.

Lee, D.R., 1985, Method for locating sediment anomalies in lakebeds that can be caused by groundwater flow: Journal of Hydrology, v. 79, p.187-193.

Lovering, T.S., and Morris, H.T., 1965, Underground temperatures and heat flow in the East Tintic District, Utah: Geological Survey Professional Paper 504-F, 27 p.

Mitchell, K.C., James, L.G., Elgar, S., and Pitts, M.J., 1990, Characterizing cyclic water-level fluctuations in irrigation canals: Journal of Irrigation and Drainage Engineering, v. 116, no. 2, p. 261-272.

Nasser, I.N., and Horton, R., 1992, Simultaneous transfer of heat, water, and solute in porous media-I. Theoretical development and II. Experiment and analysis: Soil Science Society of America Journal, v. 56, p. 1350-1365.

Nightingale, H.I., 1975, Groundwater recharge rates from thermometry, Ground Water, v. 18, no. 4, p. 340-344.

Nimmo, J.R., Deason, J.A., Izbicki, J.A., and Martin, P., 2002, Evaluation of unsaturated zone water fluxes in heterogeneous alluvium at a Mojave Basin site: Water Resources Research, v. 38 , no. 10 , p. 33-1 to 33-13.

Nimmo, J.R., Healy, R.W., and Stonestrom, D.A., 2005, Chapter 170, Aquifer recharge, in Anderson, M.G., ed., Encyclopedia of hydrological sciences: New York, John Wiley \& Sons, p. 2229-2246, doi:10.1002/0470848944.hsa161a.

Nimmo, J.R., and Miller, E.E., 1986, The temperature dependence of isothermal moisture vs. potential characteristics of soils: Soil Science Society of America Journal, v. 50, no. 5, p. 1105-1113.

Niswonger, R.G., and Prudic, D.E., 2003, Modeling heat as a tracer to estimate streambed seepage and hydraulic conductivity, in Stonestrom, D.A., and Constantz, J., eds., Heat as a tool for studying the movement of ground water near streams: U.S. Geological Survey Circular 1260, p. 81-89.

Norris, S.E., and Spieker, A.M., 1962, Temperature-depth relations in wells as indicators of semiconfining beds in valleytrain aquifers: U.S. Geological Survey Professional Paper 450-B, p. B103-B105.

Peerklamp, P.K., 1944, Bodenmeteorologische onderzoekingen te Wageningen: Meded Landbouwhogeschool Wageningen, v. 47, no.3, p. 1-96. 
Philip, J.R., and de Vries, D.A., 1957, Moisture movement in porous materials under temperature gradients: Eos (American Geophysical Union Transactions), v. 38, p. 222-232.

Poeter, E.P., and Hill, M.C., 1998, Documentation of UCODE, a computer code for universal inverse modeling: U.S. Geological Survey Water-Resources Investigations Report 98-4080, 116 p.

Pruess, K., Oldenburg, C., and Moridis, G., 1999, TOUGH2 User's guide, version 2.0: Berkeley, Calif., Lawrence Berkeley National Laboratory Report LBNL-43134, 196 p.

Ren, T., Kluitenberg, G.J., and Horton, R., 2000, Determining soil water flux and pore water velocity by a heat pulse technique: Soil Science Society of America Journal, v. 64, p. 552-560.

Ren, T., Noborio, K., and Horton, R., 1999, Measuring soil water content, electrical conductivity and thermal properties with a thermo-TDR probe: Soil Science Society of America Journal, v. 63, p. 450-457.

Reiter, M., 1999, Hydrogeothermal studies on the southern part of Sandia National Laboratories/Kirtland Air Force Base-Data regarding ground-water flow across the boundary of an intermontane basin, in Haneberg, W.C., Mozley, P.S., Moore, J.C., and Goodwin, L.B., eds., Faults and subsurface fluid flow in the shallow crust: Geophysical Monograph Series, v. 113, p. 207-222.

Reiter, M., 2001, Using precision temperature logs to estimate horizontal and vertical groundwater flow components: Water Resources Research, v. 37, no. 3, p. 663-674.

Richards, L.A., 1931, Capillary conduction of liquids in porous mediums: Physics, 1, p. 318-333.

Ronan, A.D., Prudic, D.E., Thodal, C.E., and Constantz, J., 1998, Field study and simulation of diurnal temperature effects on infiltration and variably saturated flow beneath an ephemeral stream: Water Resources Research, v. 34, no. 9, p. 2137-2153.

Rorabaugh, M.I., 1956, Ground water in northwestern Louisville, Kentucky: U.S. Geological Survey Water Supply Paper 1360-B, p. 101-169.

Rose, D.A., 1963, Water movement in porour materials, part 2-The separation of the components of water movement: British Journal of Applied Physics, v. 14, p. 491-496.

Scanlon, B.R., 1994, Water and heat fluxes in desert soils-1. Field studies: Water Resources Research, v. 30, no. 3, p. 709-719.

Scanlon, B.R., and Milly, P.C.D., 1994, Water and heat fluxes in desert soils-2. Numerical simulations: Water Resources Research, v. 30, no. 3, p. 721-733.

Schneider, R., 1972, Distortions of the geothermal field in aquifers by pumping: U.S. Geological Survey Professional Paper 800-C, p. 267-270.
Selker, J.S., Thévenaz, L., Huwald, H., Mallet, A., Luxemburg, W., van de Giesen, N., Stejskal, M., Zeman, J., Westhoff, M., and Parlange, M.B., 2006, Distributed fiberoptic temperature sensing for hydrologic systems: Water Resources Research, v. 42, doi:10.1029/2006WR005326.

Silliman, S.E., and Booth, D.F., 1993, Analysis of time-series measurements of sediment temperature for identification of gaining versus losing portions of Juday Creek, Indiana: Journal of Hydrology, v. 146, p. 131-148.

Silliman, S.E., Ramirez, J., and McCabe, R., 1995, Quantifying downflow through creek sediments using temperature time series-One-dimensional solution incorporating measured surface temperature: Journal of Hydrology, v. 167, p. 99-119.

Simunek, J., Sejna, M., and van Genuchten, M.T., 1998, The Hydrus-1D software package for simulating the onedimensional movement of water, heat, and multiple solutes in variably-saturated media-version 2.0: Riverside, Calif., U.S. Salinity Laboratory, Agricultural Research Service, U. S. Department of Agriculture, $178 \mathrm{p}$.

Smith, G.E.P., 1910, Groundwater supply and irrigation in the Rillito Valley: Tucson, Ariz., University of Arizona Agricultural Experiment Station, Bulletin no. 64, p. 81-243.

Smith, L., Forster, C., and Woodbury, A., 1989, Numerical simulation techniques for modeling advectively-disturbed thermal regimes, in Beck, A.E., Garven, G., and Stegena, L., eds., Hydrogeological regimes and their subsurface thermal effects: American Geophysical Union, Geophysical Monograph 47, p. 7-21.

Sophocleous, M., 1979, Analysis of water and heat flow in unsaturated-saturated porous media: Water Resources Research, v. 15, no. 5, p. 1195-1206.

Sorey, M.L., 1971, Measurement of vertical ground-water velocity from temperature profiles in wells: Water Resources Research, v. 7, no. 4, p. 963-970.

Stallman, R.W., 1960, Notes on the use of temperature data for computing ground-water velocity: Nancy, France, 6th Assembly on Hydraulics, Societe Hydrotechnique de France, question 1, report 3, p. 1-7.

Stallman, R.W., 1963, Computation of ground-water velocity from temperature data, in Bentall, R., ed., Methods of collecting and interpreting ground-water data: U.S. Geological Survey Water-Supply Paper 1544-H, p. 36-46.

Stallman, R.W., 1965, Steady one-dimensional fluid flow in a semi-infinite porous medium with sinusoidal surface temperature: Journal of Geophysical Research, v. 70, no. 12, p. 2821-2827.

Stevens, H.H. Jr., Ficke, J.F., and Smoot, G.F., 1975, Water temperature-Influential factors, field measurement, and data presentation: U.S. Geological Survey Techniques of Water-Resource Investigations, book 1, chap. D1, 65 p. 
Stewart, A.E., and Constantz, J.E., 1999, Measurement techniques to identify spatial and temporal patterns of streamflow in large ephemeral streams [abs.]: GSA Abstracts with Programs, v. 31, no. 7, p. A150-A151.

Stewart, A.E., 2003, Temperature based estimates of streamflow patterns and seepage losses in ephemeral channels: Stanford, Calif., Stanford University, Ph.D. dissertation, 248 p.

Stonestrom, D.A., and Blasch, K.W., 2003, Determining temperature and thermal properties for heat-based studies of surface-water ground-water interactions, in Stonestrom, D.A., and Constantz, J., eds., Heat as a tool for studying the movement of groundwater near streams: U.S. Geological Survey Circular 1260, p. 73-80.

Stonestrom, D.A., Prudic, D.E., Laczniak, R.J., and Akstin, K.C., 2004, Tectonic, climatic, and land-use controls on ground-water recharge in an arid alluvial basin: Amargosa Desert, U.S.A., in Hogan, J.F., Phillips, F.M., and Scanlon, B.R., eds., Groundwater recharge in a desert environmentThe southwestern United States: American Geophysical Union, Water Science and Applications Series, v. 9, p. 29-47, doi:10.1029/0009WSA03.

Supko, D. J., 1970, Subsurface heat flow as a means for determining aquifer characteristics in the Tucson Basin, Pima County, Arizona: Tucson, Ariz., University of Arizona, unpublished $\mathrm{Ph}$.D. dissertation, $184 \mathrm{p}$.

Suzuki, S., 1960, Percolation measurements based on heat flow through soil with special reference to paddy fields: Journal of Geophysical Research, v. 65, no.9, p. 2883-2885.

Taniguchi, M., and Sharma, M.L., 1990, Solute and heat transport experiments for estimating recharge: Journal of Hydrology, v. 119, p. 57-69.

Taniguchi, M., and Sharma, M.L., 1993, Determination of groundwater recharge using the change in soil temperature: Journal of Hydrology, v. 148, p. 219-229.

Tsang, C.F., and Hopkins, D.L., 1982, Aquifer thermal energy storage-A review, in, Narasimham, T.N., ed., Recent trends in hydrogeology: Geological Society of America, Special Paper 189, p. 427-441.

van Genuchten, M.T., Leij, F.J., and Lund, L.J., eds., 1992, Indirect Methods for Estimating the Hydraulic properties of Unsaturated Soils: Riverside, University of California at Riverside, 718 p. van der Kamp, G., and Bachu, S., 1989, Use of dimensional analysis in the study of thermal effects of various hydrogeological regimes, in Beck, A.E., Garven, G., and Stegena, L., eds., 1989, Hydrogeological regimes and their subsurface thermal effects: American Geophysical Union, Geophysical Monograph 47, p. 23-28.

van Orstrand, C.E., 1934, Temperature gradients, in Wrather, W.E., and Lahee, F.H., eds., Problems of Petroleum Geology: Tulsa, Okla., American Association of Petroleum Geologists, p. 989-1021.

van Wijk, W.R., and de Vries, D.A., 1963a, Periodic temperature variations, in van Wijk, W.R., ed., Physics of plant environment ( $2 \mathrm{~d}$ ed.): Amsterdam, North-Holland Publishing Co., p. 102-143.

van Wijk, W.R., and de Vries, D.A., 1963b, The atmosphere and the soil, in van Wijk, W.R., ed., Physics of plant environment (2d ed.): Amsterdam, North-Holland Publishing Co., p. 17-61.

Voss, C.I., 1984, A finite-element simulation model for saturated-unsaturated, fluid-density dependent groundwater flow with energy transport or chemically-reactive singlespecies solute transport: U.S. Geological Survey WaterResources Investigations Report, 84-4369, 409 p.

Walvoord, M.A., Stonestrom, D.A., Andraski, B.J., and Striegl, R.G., 2004, Constraining the inferred paleohydrologic evolution of a deep unsaturated zone in the Amargosa Desert: Vadose Zone Journal, v. 3, no. 2, p. 502-512.

Wang, K., Shen, P., and Beck, A.E., 1989, A solution to the inverse problem of coupled hydrological and thermal regimes, in Beck, A.E., Garven, G., and Stegena, L., eds., 1989, Hydrogeological regimes and their subsurface thermal effects: American Geophysical Union, Geophysical Monograph 47, p. 7-21.

Wankiewicz, A., 1984, Hydrothermal processes beneath Arctic river channels: Water Resources Research, v. 20, no. 10, p. 1417-1426.

Warrick, A.W., 2003, Soil water dynamics: New York, Oxford University Press, $391 \mathrm{p}$.

Wierenga, P.J., Hagan, R.M., and Nielsen, D.R., 1970, Soil temperature profiles during infiltration and redistribution of cool and warm irrigation water: Water Resources Research, v. 6 , no. 1, p. 230-238. 